\title{
EL BARÓMETRO Y LOS PROYECTOS METEOROLÓGICOS DE LA ILUSTRACIÓN: EL CASO ESPAÑOL
}

\author{
VÍCTOR GUIJARRO \\ Universidad Rey Juan Carlos
}

ABSTRACT: In Spain, apart from popular uses, the barometer was concieved in the $18^{\text {th }}$ Century to supply cuantitative observations in order to establish climatic parameters. These projects were supported by a dominant utilitarian mentality: after the examination of data it was supposed that relevant conclusions could be obtained for the knowledge of healthy environmental conditions as well as for the improvement of agricultural skills. This, in turn, focused the attention on a type of barometer in which reliability, and not extreme precision, was the priority.

\section{Introducción}

El barómetro conoció una extraordinaria difusión en el Siglo de las Luces. Su construcción relativamente sencilla, su amplia variedad de aplicaciones y la facilidad que ofrecía la interpretación de sus lecturas, esta vez como útil para la predicción del tiempo, explican su presencia en diversos centros, dependencias y en las manos de particulares. El éxito y las expectativas despertadas por el barómetro son pues comparables o quizás mayores que las producidas por otros instrumentos de la época como el microscopio y el telescopio.

Inventado a mediados del XVII, desde un principio se advirtieron dos usos principales que marcarían su desarrollo posterior: la determinación del tiempo atmosférico y el cálculo de la altura de las montañas. En el marco ya de la ciencia ilustrada, en el que se promueve el estudio y racionalización de la naturaleza mediante la atención a los fenómenos y la recopilación de observaciones, así como los presupuestos de la ciencia útil, las dos finalidades mencionadas encon- 
traron un suelo fértil. Así, el barómetro acompañó a geógrafos y físicos en sus expediciones terrestres o marítimas destinadas a estudiar los rasgos climáticos de territorios inexplorados o a examinar con mayor rigor el propio. De igual forma, lo encontramos en el equipaje de investigadores convertidos a montańeros que en sus excursiones, sobre todo por los Alpes pero también en El Teide, advierten y analizan las variaciones de la columna de mercurio, a veces menos regulares que lo deseado, con respecto a la altura. Con similares propósitos, a finales de siglo se incorpora al acervo instrumental de los científicos aventureros que se embarcan en los globos aerostáticos, como se comprueba en uno de los artículos que acompaña este número.

Pero también, y este es el asunto central de este trabajo, el barómetro junto con otros instrumentos se empleó para proporcionar colecciones diarias de registros cuantitativos cuya finalidad era contar, una vez realizados los cálculos medios y seleccionados los valores extremos, con una descripción del temperamento y constitución de la atmósfera de una localidad determinada, o bien, con propósitos comparativos, de otros puntos geográficos. Con esta última idea surgieron los proyectos cooperativos conocidos como redes meteorológicas, que ya cuentan con antecedentes en el siglo XVII. Proyectos que, además, proporcionaban conocimientos útiles aplicables tanto a la medicina como a la agricultura. Entre otros elementos, estos trabajos serían inviables sin la disposición de un barómetro fiable y estandarizado cuyas lecturas pudieran contrastarse con las facilitadas por los instrumentos dispuestos en lugares diferentes.

En las líneas que siguen se examinará el alcance y dimensiones que adquirieron estos proyectos en España, donde si bien, como se comprobará, existieron diversas iniciativas que asumían la recopilación de observaciones sistemáticas, no se llegó a contar con un centro coordinador de una red nacional o internacional, hecho que sí ocurriría en otros paises (en Inglaterra, J. Jurin y la Sociedad Real londinense; en Francia, la Sociedad Real de Medicina de París, y la Sociedad Meteorológica Palatina en Alemania). De las labores emprendidas en nuestro país se destacará el papel desempeñado por el instrumento mencionado para llevar a cabo estos propósitos, así como los efectos que estos trabajos tuvieron en los estudios que pretendían promover su uso y adaptación a las finalidades propuestas. Ámbitos, estos últimos, donde sobresalen las figuras de F. Salvá y V. Alcalá Galiano.

Previamente se ofrecen como introducción unos comentarios sobre los problemas fundamentales que determinaron la evolución de este instrumento en general. 


\section{Técnica y práctica del barómetro: los problemas fundamentales}

Todo el complejo de utilidades señaladas anteriormente centró la atención en el perfeccionamiento técnico del barómetro, fin al que se dedicaron con una aproximación empírica científicos y fabricantes. A partir de las obras clásicas dedicadas al estudio de la historia del barómetro así como a la instrumentación científica en general ${ }^{1}$ pueden determinarse las cuestiones pendientes que permitirían, una vez resueltas, disponer de un utillaje fiable ajustado a las necesidades prácticas. El resultado fue una amplia diversidad de propuestas que incluían diseños diversos, tablas de corrección, leyes empíricas y estudios de las propiedades de los materiales empleados. En síntesis, los problemas pendientes de los barómetros se agrupan en las siguientes categorías.

Fiabilidad. Este ámbito comprende las labores destinadas a atenuar o anular cualquier efecto que desvirtuara la comparabilidad de los barómetros. Uno de los hechos conocidos desde el s. XVII era que la presencia de aire en el mercurio y en el espacio reservado al vacío en el tubo provocaba la inexistencia de una variación constante de la columna. De forma accidental, en el año $1723^{2}$ se descubrió y comenzó a emplear un método, consistente en la cocción del mercurio combinada con el empleo de una varilla de hierro caliente introducida en el tubo, que se demostró eficaz para lograr el fin deseado. A lo largo del s. XVIII se encuentran referencias a esta técnica con leves variaciones. Junto a estos requerimientos se precisaba igualmente comprobar la uniformidad del diámetro interno del tubo.

Observación-medición. Diversos factores podían falsear las medidas obtenidas, especialmente cuando se demandaba un determinado nivel de precisión. Los fundamentales eran: problemas en el mantenimiento del nivel cero en la cisterna de los barómetros, capilaridad, defectos en la división de la escala y efectos de la temperatura, tanto en la columna de mercurio (que podía llegar a una diferencia de $13 \mathrm{~mm}$. entre los puntos de congelación y ebullición) como en la esca-

${ }^{1}$ Destacan W. E. K. Middleton, The History of the Barometer, Baltimore: John Hopkins, 1964 e Invention of the Meteorological Instruments, Baltimore: John Hopkins, 1969; M. DAUMAS, Les instruments scientifiques aux XVIIe et XVIIIe sizcles, París: Press Universitaires de France, 1953; T. S. FELDMAN, «Barometer", R. BUDD y D. J. WARNER (eds.), Instruments of Science. An Historical Encyclopedia, Londres: The Science Museum, 1998, 52-54, y A. WOLF, A History of Science, Technology and Philosophy in the $18^{\text {th }}$ Century, Londres: Goerge Allen, 1952 (22 ed.), pp. 274-341.

2 Daumas, opus cit., 273; Middleton, The History, opus cit., 243. 
la. La elevación y descenso del mercurio produce una variación del nivel cero, el marcado por la superficie del líquido en el depósito, dependiendo esta magnitud de la razón entre la sección del diámetro interno y el correspondiente de la cisterna. Era pues una cifra fácil de calcular. Se introdujeron, con el fin de compensar el efecto, las escalas corregidas ${ }^{3}$ y también diversos diseños de cisterna a lo largo del siglo. En cuanto a la capilaridad, el hecho de que la superficie del mercurio no fuera plana podía producir una alteración en las mediciones, mayor a medida que disminuimos el diámetro interno del tubo. Sobre los efectos de las diferencias de temperatura, durante la última parte del XVIII y primeras décadas del XIX se realizaron diversos estudios experimentales que permitieron la confección de tablas de corrección o la determinación de la magnitud correspondiente a la dilatación media de la columna barométrica producida entre los puntos de congelación y ebullición del termómetro ${ }^{4}$. Por último, respecto de la división de la escala, también en el último cuarto del siglo se produjeron cambios significativos: se sustituyeron las escalas de papel por las de metal, y para la graduación de estas se disponía de un sistema mecanizado gracias a la existencia de la máquina de dividir de J. Ramsden (para escalas circulares desde 1766 y para las lineales desde $1768^{5}$ ).

Transporte. Debe distinguirse en este ámbito entre los que se diseñaban simplemente para soportar el viaje sin sufrir daños hasta el lugar en el que se emplearían como barómetros fijos y aquéllos empleados permanentemente como barómetros portátiles, grupo en el que se incluirían los destinados a las observaciones hipsométricas. Aunque en los primeros se tomaban diversas precauciones, es en estos últimos donde la técnica de fabricación se esmeraba al máximo para conseguir evitar la ruptura del vidrio por los golpes del líquido así como para mantener el nivel cero en la cisterna (innecesario en los de sifón).

Mientras que el primer y el tercer factor (comparabilidad y transporte) eran fundamentales en las observaciones meteorológicas, el segundo era un problema secundario, o bien irrelevante, debido a que estos errores comienzan a ser significativos a partir de un nivel justificado de sensibilidad, no demandado, como se verá, en las estimaciones de la meteorología del setecientos. Por el

${ }^{3}$ En 1792, Middleton, ibid, 182.

4 V. Ibid., pp. 179-180.

5 R. C. BROOKS, "Dividing engine", R. BUDD y D. J. WARNER (eds), opus cit., p. 186. 
contrario, el segundo factor es de importancia vital en las mediciones hipsométricas, vinculadas a la tradición de las labores topográficas y de las matemáticas prácticas. Después de los trabajos de Jean André de Luc ${ }^{6}$ (autor de la influyente obra Recherches sur les modifications de l'atmosphère, 1772), cuyos barómetros podían estimar medidas de $1 / 16$ de línea $^{7}$ (aprox. $0,14 \mathrm{~mm}^{8}{ }^{8}$ ), se adopta como una práctica necesaria la determinación de los factores térmicos, de capilaridad, etc., ya que su influencia se apreciaba en los márgenes de precisión aceptados para los cálculos de la altura de una montaña (cuyos errores se movían en torno a los $0,2 \%$ y $0,7 \%$ de los valores reales) ${ }^{9}$.

\section{El barómetro y la medicina}

El conocimiento de las condiciones climáticas locales podía ser fundamental, se pensaba, tanto para la medicina como para la agricultura. En el primer caso, estas ideas (relación entre las causas ambientales, como el clima, y las enfermedades) se tenían en cuenta ya en las civilizaciones más antiguas; sin embargo es a partir de los estudios de Hipócrates cuando se establece de forma sistemática una relación directa entre la salud y el clima ${ }^{10}$. Bastante más tarde, ya en el s. XVII, esta asociación sería defendida en sus estudios médicos por T. Sydenham en Inglaterra, quien en un principio estableció patrones estacionales de enfermedades. Ya a finales de su carrera y probablmente influido por las observaciones meteo-

${ }^{6}$ Sobre los cambios post 1770 y la influencia de de Luc, T. S. FELDMAN, «Late Enlightenment Meteorology", T. FränGSMYR, J. L. HeILBRON y R. E. RIDER (eds.), The Quantifying Spirit in the $18^{\text {th }}$ Century, Berkeley: University of California Press, 1990, pp. 143-178; espec. 153-158.

${ }^{7} 1$ pie $=12$ pulgadas; 1 pulgada $=12$ líneas. Por otra parte, 1 pul. castellana $=2,8 \mathrm{~cm} ; 1$ pul. francesa $=2,7 \mathrm{~cm} . ; 1$ pul. inglesa $=2,54 \mathrm{~cm}$.

${ }^{8}$ Recordemos que una diferencia de $1 \mathrm{~mm}$. en la columna corresponde, dependiendo de la temperatura y de la presión medida en ese momento, como mínimo a 10,24 m. y como máximo a $13,37 \mathrm{~m}$.

${ }^{9}$ Acerca de estas labores, T. S. FELDMAN, "Applied mathematics and the quantification of experimental physics: The example of barometric hypsometryn, Historical Studies in the Physical Sciences, 15 (1985): 127-197, espec. para las cuestiones tratadas, 168-178.

10 F. SARGEANT II, Hippocratic Heritage. A History of Ideas About Weather and Human Health, Nueva York, Pergamon Press, 1982, 50-51; Sobre los aires, aguas y lugares (Tratados hipocráticos, Madrid, Gredos, 1986, 7 vols., vol. II, pp. 39-88) es la obra de Hipócrates en la que se desarrollan estas concepciones; sobre este tema véase igualmente P. LAÍN ENTRALGO, Historia de la medicina, Barcelona, Salvat, 1978, p. 317, y sobre la influencia de estas ideas en el XVIIl español, J. L. Peset, "La enfermedad y los enfermos», en J. L. PESET (dir.), Historia de la ciencia y de la técnica en la corona de Castilla, Valadolid: Consejería de Educación y Cultura, 2002, vol. IV, pp. 223-228. 
rológicas de sus contemporáneos (R. Hooke, C. Wren y J. Locke), efectuadas mediante instrumentos, las investigaciones se volvieron algo más detalladas, aunque no perdieron el estilo cualitativo que caracterizó su obra ${ }^{11}$. Precisamente es en el contexto anterior, el promovido por miembros destacados de la Royal Society (entre los que también se encontraba $R$. Boyle) en el que surge la idea de mantener un diario médico meteorológico. Siguiendo estas propuestas, en el s. XVIII destacan algunos personajes por el mantenimiento de este tipo de registros sistemáticos en los que se combinan los datos locales del tiempo con la información de diferentes efermedades. Durante este tiempo los diarios tuvieron un carácter descriptivo y provisional (se afirmaba que en cualquier caso podían ser útiles para la posteridad); estaban pues exentos de vínculos correlativos entre los dos ámbitos señalados ${ }^{12}$. Con intenciones similares, ya fuera de Inglaterra, la Sociedad Real de Medicina de París llevará a cabo un proyecto, dirigido por L. Cotte $^{13}$, que pretendía reunir la información procedente de numerosos observatorios franceses y de otros países ${ }^{14}$.

No se han encontrado evidencias acerca de una relación directa entre las sugerencias de los científicos ingleses y el inicio de una actividad similar en España. Solamente ha podido constatarse que en nuestro país esta asociación, convertida en un motivo de investigación, se remonta al menos a la década de 1730 , cuando en el seno de la Real Academia de Medicina de Madrid se llevaron a cabo unas efemérides barométrico-médicas cuya intención era el establecimiento de relaciones entre el estado evolutivo de las afecciones sufridas en Madrid y las variaciones de la presión atmosférica ${ }^{15}$.

11 SARGEANT, opus cit., p. 156.

12 V. ibid., pp. 292-3 y 307 y ss. "Tanto los diarios de Hillary como los de Fothergill contienen series de datos meterológicos y estimaciones mensuales de enfermedades dominantes. El tiempo se medía con instrumentos meteorológicos precisos; la incidencia y permanencia de la enfermedad con términos cuantitativos vagos, como algo, poco, mucho y epidémicon (ibid., pp. 308-9).

13 PERE LOUIS COTTE (1740-1815), figura central de la meteorología ilustrada, es autor de Traité de Météorologie (París, 1774) y Mémoires sur la Météorologie (París, 1788).

14 Se publicarian los diferentes informes a partir de 1779 en Histoire de la Société Royale de Médicine, avec les memoires de médicine; sobre la Sociedad, T. S. FeldMaN, The History of Meteorology, 1750-1800. A Study in Quantification of Experimental Physics, tesis leida en Universidad de California, Berkeley, 1983, pp. 242-249.

15 Sobre estas labores, V. Matilla, Historia de la Real Academia Nacional de Medicina, Madrid, 1984, pp. 18-40, y del mismo autor, "Real Academia de Medicina", en Las Reales Academias del Instituto de Espafia, Madrid: Alianza Editorial, 1992, pp. 339-383, espec. pp. 347-8. 
Las observaciones diarias del barómetro y el termómetro, encargadas a $\mathrm{F}$. Fernández de Navarrete (médico de Felipe V), se iniciaron en marzo de 1737. Su motivo era la relación ya comentada, puesta de manifiesto por sus promotores con las siguientes palabras:

Lo que ofrece la combinada observación esta a la vista: sus primeros legisladores vocearon la mutua dependencia, y consonancia entre la Atmosphera, sus condiciones, y mudanzas, y el estado, y alteraciones de nuestro cuerpo, como mundo menor, cuya conservacion en el todo depende del mayor $^{16}$.

Para ello se emplearon instrumentos que, como primera condición, debían ser de "facilisimo manejo", hecho que significaba, en el caso del barómetro, ignorar por razones de simplicidad las posibles variaciones existentes entre los diferentes países (probablemente en las escalas y sus medidas) expresadas por la Academia de Ciencias de París en 1699 o la influencia de la temperatura en las alteraciones de la columna de mercurio, observación puesta de manifiesto por Amontons ${ }^{17}$. Para los académicos se podía prescindir de estas y otras correcciones; era suficiente con la disposición de un instrumento que provisionalmente sirviese a los propósitos precedentes. Se eligió el "comun barometro de Inglaterra", consistente, según la descripción, en un tubo provisto de una curvatura en la parte inferior que finalizaba en una ampolla cilíndrica « 14 veces mas ancha que el Tubo" ${ }^{18}$, lo cual, dada la proporción, evitaría al menos el incómodo efecto de la variación de nivel cero de la cisterna, comentado anteriormente.

Así pues, la tabla con las observaciones debía contener indicaciones diarias sobre el viento (pero exentos de "prolijidad matemática", es decir, desprovisto de anotaciones sobre variaciones producidas cada hora, minuto, etc.). También debían aparecer las indicaciones termométricas, así como del tipo de día dominante (sereno, nublado, etc.), del temple del aire (caliente, frío, templado,...), de los fenómenos o meteoros notables (por ejemplo, eclipses), de las fases de la Luna y,

${ }^{16}$ F. FERNANDEZ NAVARRETE, Ephemerides barometrico-medicas matritenses, Madrid, 1737. "Intro.", s/p.

${ }^{17}$ Ibid., s/p

${ }^{18}$ Ibid. 
en la primera columna, las correspondientes lecturas barométricas. Estas últimas se distinguirían por un símbolo (*) que aludía a la media de su movimiento, según la latitud del "Barómetro simple de Inglaterra»" ${ }^{19}$ y una cifra o dos (si se ha hecho más de una obervación en el día, en cuyo caso se añadía un punto de separación) referida a la línea de la escala en la que se hubiera detenido el nivel de mercurio, ya fuera por encima (en cuyo caso se dispondría sobre el símbolo) o por debajo de la media ${ }^{20}$. El resultado, relacionado como ejemplo con los cinco primeros días de marzo, sería aproximadamente como sigue:

\begin{tabular}{|c|c|c|c|c|c|c|c|}
\hline Dias & $\begin{array}{l}\text { Sitios del } \\
\text { barómetro }\end{array}$ & Vientos & Tiempo & Luna & $\begin{array}{l}\text { Sitio del } \\
\text { termómetro }\end{array}$ & $\begin{array}{l}\text { Temple } \\
\text { del aire }\end{array}$ & Meteoros \\
\hline 1 & 5 & $E$ & $S$ & 0 & $\stackrel{*}{14}$ & $\mathrm{~T}$ & $\begin{array}{l}\text { Eclipse } \\
\text { solar visible } \\
\text { Desapareció } \\
\text { el cometa }\end{array}$ \\
\hline 2 & 5 & $\mathrm{E}$ & $S$ & & $\begin{array}{c}* \\
14 \\
\end{array}$ & $\mathrm{~T}$ & \\
\hline 3 & $\begin{array}{c}5.4 \\
*\end{array}$ & Es & V & & $\stackrel{*}{10}$ & $\mathrm{~T}$ & \\
\hline 4 & 5 & Es & $S$ & & * 14 & $\mathrm{~T}$ & \\
\hline 5 & $\begin{array}{c}6.5 \\
* \\
\end{array}$ & Es & V & & $\begin{array}{c}* \\
14 \\
\end{array}$ & $T$ & \\
\hline$\cdots$ & $\cdots$ & $\ldots$ & $\ldots$ & $\ldots$ & $\ldots$ & $\ldots$ & $\ldots$ \\
\hline
\end{tabular}

Una vez reunidos los datos para todo el mes se realizaba un comentario general sobre las lecturas barométricas, termométricas, vientos dominantes, y hechos destacados relativos a la salud, que incluyen referencias a enfermedades, epidemias, etc. En particular, los análisis centrados en el barómetro referentes a ese mes subrayaban la moderación del peso de la atmósfera en relación con el in-

${ }^{19}$ Detalle que había que tener en cuenta cuando se trasladaba un barómetro de un lugar a otro con altura media significativamente diferente, especialmente si tenían indicaciones en la escala referidas al tiempo que coincidían con niveles especificos de la graduación (solamente válidos para el lugar de fabricación); de ahí que en modelos posteriores estas indicaciones se realizaran sobre una placa corrediza ajustable al lugar de uso.

${ }^{20}$ NAVARRETE, opus cit, p. 1. 
vierno anterior y se destacaban los valores extremos producidos durante este período ("el dia de menor peso del ayre en Madrid, fue el dia 10, que baja a $\left.{ }^{*} 4\right)^{21}$.

En realidad, la información aquí presentada es la correspondiente a la publicación de Fernández Navarrete del año 1737. Los registros relativos a años posteriores, que se prolongan hasta el año 1746, se encuentran en la documentación de la Real Academia ${ }^{22}$. Se advierten entre la tabla del primer año y las de años posteriores sensibles diferencias: por ejemplo, el primer año se tomaban seis observaciones diarias; el segundo tres, y los siguientes disminuyeron hasta dos al día. Por otra parte, estas no incorporan los datos astronómicos encontrados en la obra publicada ni los datos médicos.

Como se ve, el uso del barómetro no tiene un propósito predictivo, ni obviamente tampoco sus lecturas son cantidades que se empleen en el seno de una formulación matemática, como correspondería en los cálculos hipsométricos. En realidad se trata de una serie de referencias que pretenden contribuir al comentario sobre el estado general del ambiente, haciéndolo, eso sí, aparentemente más preciso mediante la incorporación de las cifras que aparecen en las diferentes columnas de la tabla. Se diferencia de otros trabajos similares, esta vez mediante la creación de redes meteorológicas internacionales, por ejemplo de la coordinada por el secretario de la Royal Society londinense J. Jurin ${ }^{23}$, en la mayor simplicidad de las reunidas por la Academia de Medicina de Madrid y en la insercción de las referencias astronómicas. Las de Jurin, distribuidas en 1723, incluían medidas sobre la fuerza del viento y de las precipitaciones, precisamente los datos que aquí se consideran irrelevantes. Pero se asemeja en los comentarios que acompañan a los diferentes valores, tendencia extendida durante estos años ${ }^{24}$.

${ }^{21}$ V., por ejemplo, ibid., pp. 4-7.

22 Real Academia NaCional de Medicina, "Efemérides barmétrico-médicas de 1742», leg 8c, doc 34b, y "Efemérides barométrico-médicas del año 1744", leg 8c, doc. 33a.

${ }^{23}$ Philosophical Transactions, 1723, Vol. 32, p. 422.

24 J. GOLINSKI ("Barometers of Change: Meteorological Instruments as Machines of Enlightenment", en W. CLARK et al., eds., The Sciences in Enlightened Europe, Chicago: The University of Chicago Press, 1999, pp. 69-93; v. pp. 87-88) cita algunas notas enviadas por J. Horsley a Jurin en 1723 donde aparecen estas referencias a enfermedades acompaniando a los comentarios de las lecturas de instrumentos, una costumbre, según comenta, ampliamente difundida en la época, encontrándose ejemplos en publicaciones periódicas como el Gentelman's Magazine. 
En la segunda mitad del XVIII esta asociación entre el estado de la atmósfera y las enfermedades volverá a ser reclamada por autores españoles pero esta vez, como se verá, dentro de los proyectos meteorológicos que tenían un propósito más general.

\section{El barómetro y las redes meteorológicas}

El establecimiento de redes de observadores, cuyos antecedentes se remontan a mediados del s. XVII (es decir, poco después de la propia invención del baroscopio, convertido posteriormente en barómetro), no tenía ólo el propósito de determinar las correlaciones específicas de la supuesta influencia del medio ambiente en las enfermedades. También se constituyeron con la convicción de que la reunión de las lecturas ofrecidas por los instrumentos, acompañadas de otros datos, contribuiría de manera esencial al establecimiento de valores estadísticos medios y extremos (de temperatura, presión y lluvia) de carácter local, valores que podrían compararse con los recabados en otros lugares ${ }^{25}$.

En este contexto se insertan los trabajos de F. Salvá, médico y autor de diversos estudios relativos a la medicina, la electricidad, telegrafía, máquinas y —el asunto que aquí nos interesa - meteorología. Sobre los anteriores temas se conocen sus aportaciones ${ }^{26}$, sin embargo el último de los aspectos mencionados ha sido objeto de escasa atención ${ }^{27}$. Las contribuciones de Salvá que nos interesan

${ }^{25}$ En general, acerca de la historia de las redes meteorológicas ilustradas, T. S. FELDMAN, The History of Meteorology, 1750-1800, opus cit., pp. 192-284. Se pueden considerar estas labores como un precedente, salvando las peculiaridades de cada perfodo, de la climatología del XIX, en la que el clima comienza a entenderse en un sentido moderno como un patrón atmosférico predictivo caracterizado por una serie de valores medios y aplicado a extensas áreas geográficas (v. ibid., pp. 192-3).

26 Puede consultarse, por ejemplo: S. RIERA, Ciència i tècnica a la Il.lustracid: Francisco Salvd i Campillo (1751-1828), Barcelona: Ediciones de la Magrana, 1985; J. Agust1, Ciència $i$ tècnica a Catalunya en el segle XVIII o la intruducció de la maquina de vapor, Barcelona: Institut d'Estudis Catalans, 1983; M. BARRIENDOS, "Dr. Francesc Salvà i Campillo", Treballs de la Societat Catalana de Geografia, 10, n. 39, Institut d'Estudis Catalans, Barcelona, 1995, pp. 167-173; J. M. ROMERo López, "Francisco Salvá, un ilustrado visionario y precursor de las telecomunicaciones", Jornadas sobre el Real Sitio de San Fernando de Henares en el siglo XVIII, San Fernando de Henares, 18 y 19 de octubre de 1996, pp. 231-242.

${ }^{27}$ S. RIERA (opus cit, 189-193) incluye algunos comentarios sobre estas cuestiones además de la publicación de su inédita "Memoria sobre la construcción de los instrumentos meteorológicos", 1790; por otra parte se encuentra el trabajo de M. Barriendos; J. GARCIA; J. Martín Vide; F. Nunes; J. C. Peña, y J. M. AlCoforado, "18 ${ }^{\text {th }}$ Century Instrumental 
en este estudio comprenden: memorias sobre la construcción y mejora de instrumental meteorológico ${ }^{28}$, que analizaremos posteriormente, y en el terreno práctico, observaciones meteorológicas realizadas durante aproximadamente cuarenta años, enviadas, desde 1786 al Memorial Literario Instructivo y Curioso de Madrid (mensualmente) y hasta 1827 al Diario de Barcelona (diaramente) ${ }^{29}$.

Una colaboración del médico al Memorial literario instructivo y curioso de Madrid ${ }^{\beta 0}$, donde desde su creación en $1784^{31}$ se publicaban diarios meteorológicos a los que nos referiremos más adelante, puede arrojar luz sobre las ideas de Salvá. Aquí, después de denunciar la situación de relativo retraso de la meteorología en España en comparación con otros países (Italia, Francia, Inglaterra, Rusia, Suecia, etc.), reflejado en la negativa "por dos veces" a participar en la red proyectada por la Sociedad Meteorológica Palatina ${ }^{32}$, se comentan los beneficios y sentido de estas observaciones, en las que el barómetro aparece como instrumento fundamental:

Meteorological Series in the Iberian Peninsula. General characteristics and climatic utility", comunicación presentada al congreso Giuseppe Toaldo e il Suo Tempo (1719-1797). Scienza e Lumi tra Veneto ed Europa, Padua, 10-14 de noviembre de 1997.

28 También dentro de la meteorologia habria que incluir las memorias que muestran su interés por el estudio de los higrómetros ("Sobre los higrómetros...", Real Academia de Ciencias y Artes de Barcelona, 25 de febrero de 1807, caja 19) así como de los efectos de los rayos: "Sobre la causa de la maior frequencia de herir los Raios a Barna y sus Alrededores de los que observaba antiguamente," leída en la Academia de Ciencias y Artes de Barcelona en 1790, y "Relacion del Rayo que en el dia 28 de julio cayó en Barcelona en la casa que llaman el Retirom, Memorial Instructivo, 1788.

${ }^{29}$ El conjunto de sus observaciones se publicaron en las Tablas meteorologicas, 1780-1824, 4 vols.

30 “Carta sobre la utilidad de los Diarios Meteorológicos que se insertan en esta obra periodican, Memorial literario, Madrid, 1787, pp. 112-122.

${ }^{31}$ La propia publicación comienza con una "Introduccion a las observaciones meteorologicas sobre el temple del aire de Madrid", donde se recomiendan las observaciones, de la que se beneficiarán principalmente los médicos, Mem. Lit., enero de 1784, pp. 5-9. Dos años más tarde, sin embargo, se inserta un artículo en el que se explica la verdadera dimensión de estas actividades: en contra de los falsos pronósticos de los astrólogos judiciarios (entre los que se cita a Diego de Torres Villaroel), "la colección de estas observaciones sirve de mucho para el conocimiento topografico \& c. para formar justa idea de un clima, temperamento, constitucion, \& c. aplicable a la Medicina y la Agricultura, esto es, a las enfermedades, al regimen de su curacion, a la materia medica respecto de aquella, y a la siembra y cosecha según el terreno de estas", Mem, Lit., abril de 1786, pp. 457-458.

${ }^{32}$ Indicado en el prefacio del tercer volumen de sus efemérides, Mem. Lit., 1787, p. 114. 
1. Para agricultores y médicos es suficiente con una recapitulación de las tablas, consistente en la obtención de la elevación media de los instrumentos a partir de la suma de las observaciones partida por el número de las mismas. De estos datos se deduce la frecuencia e intensidad de las variaciones de una hora del día a otra, así como se pone de manifiesto qué días fueron serenos, cuáles cubiertos, vientos, etc.

2. Pero para los físicos esto no es suficiente. Por medio de estas tablas puede, sin embargo, obtenerse igualmente información para responder a cuestiones propias de esta disciplina. Por ejemplo, se sabe que los ascensos y descensos del barómetro están motivados por la acción de la gravedad y por la variación de la elasticidad del aire, pero también se ha observado que hay otras causas que influyen en estos cambios. Para determinar estas «se requiere de los Diarios meteorologicos de varias partes, para saber en que parages son mas sensibles dichos movimientos, en que tiempos, en que horas del dia, en que temporales en cada país; á que extension de terreno llega la igualdad de las referidas oscilaciones..." ${ }^{33}$.

3. Por último, su utilidad meteorológica, es decir, como instrumento de predicción del tiempo, no quedará establecida hasta que no se hayan determinado las causas anteriores. Es sabido, afirma el autor, que por las oscilaciones del barómetro se suele saber 24 ó 48 horas antes si lloverá, si el tiempo será sereno, etc. "pues el azogue sube o baja con mucha anticipacion á estos estados. No obstante alguna vez engaña, y en otra no sucede el movimiento barometrico, que habria correspondido,..." ${ }^{34}$. Así pues, hasta que "la teoria del barometro" no esté más desarrollada no se conocerá de dónde proceden estas excepciones o en qué circunstancias las indicaciones barométricas no son válidas ${ }^{35}$. Pero esto es imposible sin contar con más observaciones y sin añadir los resultados de otros instrumentos, como el higrómetro, el eudiómetro y el electrómetro ${ }^{36}$.

${ }^{33}$ Ibid., p. 116.

${ }^{34}$ Ibid., p. 117.

${ }^{35}$ Sobre el estado de los estudios teóricos del funcionamiento del barómetro en general, que reflejan las mismas incertidumbres que aquí se expresan, W. K. MidDLETON, A History of the Theories of Rain, Nueva York: Franklin Watts, 1966, pp. 63-91.

${ }^{36}$ Mem. Lit., 1787, pp. 117-118. 
En términos similares, e incluso algo más generales, se expresa V. Alcalá Galiano $^{37}$ en la introducción a su edición de la obra de G. Toaldo (Saggio Meteorologico, Padua, 1770), publicada también en 1786. Aquí señala el alcance de la meteorología, "ciencia de la naturaleza" que comprende, siguiendo a Van Swinden ${ }^{38}$ : el conocimiento del clima y de los meteoros que se derivan de las modificaciones del aire, según las indicaciones de los instrumentos, así como el perfeccionamiento de la teoría del aire, de su elasticidad, calor, presión, movimientos ${ }^{39}, \ldots$ De esta ciencia se beneficiarán también, como ya se venía repitiendo, la medicina y la agricultura. Pero para que esto se verifique es preciso que se ordene la construcción de instrumentos, que se formen diarios y se constituyan redes de observadores, cuyos resultados, contra lo que algunos piensan en el presente, puede servir para la posteridad ${ }^{40}$. Como novedad, da un paso más respecto de otros autores: reclama el acercamiento de los matemáticos a la meteorología, hecho que permitiría la determinación de leyes y causas de los fenómenos ${ }^{41}$.

En España, por tanto, en la década de 1780 se dan los primeros pasos firmes orientados hacia el establecimiento de observatorios meteorológicos, cuyos tímidos resultados se van comprobando en algunas publicaciones periódicas como el Memorial Literario. A estas iniciativas se sumarán las políticas, como la de Rodríguez de Campomanes, presidente del Consejo de Castilla, que en 1784 enviaba instrucciones a alcaldes y regidores de diversas ciudades para que remitiesen a Madrid informes sobre lluvias, nieblas, vientos y otros meteoros que se observasen. Sin embargo, en este caso no se encontraba la exigencia del registro sistemático de las lecturas aportadas por instrumentos.

${ }^{37}$ Secretario de la Sociedad Económica de Segovia y profesor del Real Colegio de Artillería de la misma ciudad.

${ }^{38} \mathrm{~J}$. van Swinden, corresponsal de Cotte y figura destacada de la meteorología del último cuarto de siglo, momento en que la disciplina experimenta un significativo crecimiento en Europa; realizó observaciones en su país natal, Holanda, y escribió al menos dos obras relevantes, Dissertation sur la comparison des thermomètres, Amsterdam, 1778, y Mémoire sur les observations météorologiques faites a Franecker, Amsterdam, 1780.

${ }^{39}$ G. TOALdo, La Meteorología aplicada a la Agricultura, Segovia, 1786, Prólogo, VII-VIII (en ed. de J. L. GARCiA HourCADE, La meteorología en la España ilustrada y la obra de Vicente Alcalá Galiano, Segovia: Asociación Cultural «Biblioteca de Ciencia y Artillería”, 2002).

${ }^{40}$ lbid., XV.

${ }^{41}$ Ibid., XIX. 
Las contribuciones realizadas al Memorial Literario (y también al Diario Curioso de Madrid y al Diario de Barcelona), procedentes de Barcelona, Cádiz y Madrid, representan un ejemplo del alcance del trabajo que pretendía promocionarse en todo el país. Así, los datos de Barcelona se encuentran organizados de la siguiente forma ${ }^{42}$ :

Para el barómetro (cuatro primeros días),

\begin{tabular}{|l|l|l|}
\hline \multicolumn{1}{|c|}{ Mañana } & \multicolumn{1}{c|}{ Tarde } & \multicolumn{1}{c|}{ Noche } \\
\hline 28 pu. 21. $1 / 8$ & 28 pu. $2.1 .4 / 8$ & 28 pu. $2.1 .4 / 8$ \\
\hline 28.2 .4$. & 28.2 .4$. & 28.1 .6$. \\
\hline 28.1 .4$. & 28.1 .5$. & 28.1 .4$. \\
\hline 28.1 .2$. & 28.1 .6$. & 28.1 .2$. \\
\hline$\ldots$. & $\ldots$. & $\ldots$. \\
\hline
\end{tabular}

Completan la plantilla tres columnas para las medidas termométricas y tres para los vientos y estados del cielo (nubes, sereno, entrecubierto, nubes y relámpagos,...). Al final, se expone una "Recapitualción", que exlusivamente referida al barómetro (para el termómetro y la cantidad de lluvia se sigue el mismo procedimiento) contiene los siguientes cálculos:

Mayor elevación del barómetro, el día 1 y 2 ............ 28 pulgadas 2 lin 4/8 Menor, día 9 27 110

Diferencia 00 $3 \quad 4 / 8$

Elevación media 28 $0 \quad 6 / 8$

Posteriormente se afirma que se sigue el método de Cotte, cuyos datos se publican mensualmente en los "Diarios de Medicina de París". La repetición de las observaciones tres veces al día obedece igualmente a las recomendaciones de las academias extranjeras. Finaliza indicando la orientación de los instrumentos y su influencia en las medidas termométricas.

${ }^{42}$ Memorial, opus cit, agosto de 1786, pp. 477-481. 
En cuanto a los enviados desde Madrid, se observa que responden, con mínimas diferencias, al mismo patrón: las lecturas se reducen a una al día y estas difieren en el grado de precisión (entre 1784 y 1786, sólo en pulgadas y líneas; a partir de este último año, coincidiendo con las publicaciones de las tablas barcelonesas, se indican también fracciones de línea, procedimiento que también se sigue en el caso de Cádiz). Las explicaciones finales contienen comentarios similares: la constancia o no del barómetro, y se señalan algunos máximos y mínimos producidos a lo largo del mes.

Con respecto a los registros y tablas confeccionadas en otros centros europeos, sólo se diferencian en algunos detalles, como la inclusión o no de otras categorías (en las españolas es difícil encontrar datos referidos a la dirección o fuerza del viento, o bien a la humedad). Este tipo de observaciones sí se encuentran, por ejemplo, en el diario meteorológico mantenido por la Sociedad Real londinense $^{43}$ o en el más prolijo de la Sociedad Meteorológica Palatina, iniciado en 1780 , donde se recogen, entre otras, lecturas higrométricas, de declinación magnética, de viento, lluvia,... ${ }^{44}$. Si atendemos exclusivamente al barómetro, se comprueba que el tipo de lecturas, con indicación de pulgadas, líneas y fracciones, se asemeja a las llevadas a cabo en Francia, según aparecen en los diarios de la Academia Real de Ciencias ${ }^{45}$ y, como ya se había reconocido, en el Traité de Cotte. Un hecho que induce a pensar que los modelos dominantes de este tipo de proyectos procedieron del país galo.

J. Garriga, a cargo de la cátedra de Meteorología vinculada al Real Observatorio de Madrid, representa el último intento del período estudiado por introducir un estudio sistemático de la meteorología que incorporase un obligado análisis de su instrumentación. En una de sus obra, Curso elemental de meteorologia (Madrid, 1794) menciona que ésta comprende varios volúmenes y que el 5.० estaría dedicado precisamente al utillaje meteorológico. Sin embargo, sólo se publicó el primero, dedicado más bien a cuestiones astronómicas, tema justificable

43 Philosophical Transactions, 66 (1776), pp. 319-352.

44 Sobre las actividad de esta sociedad, iniciadas en 1780, J. A. Kington, "The Societas Meteorologica Palatina: An Eighteenth- Century Meteorological Societyn, Weather, 29 (1974): pp. 416-426 y D. C. Cassidy, aMeteorology in Mannheim: The Palatine Meteorological Society, 1780-1795", Stuttgart, Franz Steiner, 1985, pp. 8-25 [cit incompl] ¿??

45 Memoires de l'Academie Royale, 1781, 729 y ss. 
para el autor por la influencia de los astros en nuestro cuerpo, en las enfermedades y en el aire que nos rodea ${ }^{46}$. El gran proyecto de Garriga, como reconoce en sus publicaciones ${ }^{47}$, era la de liderar el centro coordinador de las observaciones realizadas en diversos lugares, tarea que exigiría disponer de tablas meteorológicas normalizadas y descricpiones de los instrumentos empleados en las mismas ${ }^{48}$. Proyecto que no llegó a convertirse en realidad.

Además de estos intentos por establecer y consolidar redes existieron diversas iniciativas, esta vez individuales e institucionales, por mantener registros sistemáticos, como la de Alcalá Galiano ${ }^{49}$, las de Juan López Peñalver (vinculado al Observatorio Astronómico Nacional) ${ }^{50}$, las del Marqués de Ureña en la Isla de León $\left(\right.$ Cádiz) ${ }^{51}$ y las del Observatorio Astronómico de Cádiz ${ }^{52}$. Así mismo, de manera excepcional, el barómetro se empleó para estudios de alcance más especulativo. En este último caso se encuentra A. de Ulloa (participante junto con J. Juan en la expedición geodésica hispano-francesa al virreinato de Perú, 1734-1743), quien empleó este y otros instrumentos en sus análisis y descripción de la diversidad climática de América, uno de los asuntos en los que centró sus intereses científicos ${ }^{53}$.

46 V. Curso elemental, Madrid, 1794, pp. 81 y 91.

47 Ibid., Prólogo, XIV-XV; Memorial Literario, enero de 1805, pp. 105-113.

${ }^{48}$ De hecho llegó a formular unas instrucciones generales: J. GARRIGA, "Plan del modo de hacer las obervaciones meteorológicas para que sean útiles al públicon, Real Sociedad Económica Matritense de Amigos del País, leg. 145, cit. por García HourCade, opus cit., p. 130.

${ }^{49}$ Entre 1783 y 1785, J. L. Garcia Hourcade, La meteorologia en la España ilustrada y la obra de Vicente Alcala Galiano, Segovia: Asociación Cultural "Biblioteca de Ciencia y Artillería”, 2002, p. 147.

${ }^{50}$ En torno a 1800 , recogido en M. RICO y SinOBAS, "Observaciones meteorológicas varias, 1800 a 1848", Real Academia Nacional de Medicina, 12-8, Molina-31, aunque ya se realizaban las observaciones en el centro con anterioridad.

${ }^{51}$ Realizadas en los primeros años ya del XIX y recogidas en Anales de Historia Natural (enero de 1803, primer trimestre), cit. en RICO y SINOBAS, ibid.

52 A. Lafuente y M. Sellés, El observatorio de Cádiz, 1753-1831, Madrid, Ministerio de Defensa, 1988, p. 263. Aquí se afirma que el uso de barómetros en los buques de la armada se inició a partir de 1780. El tipo de barómetro empleado en las observaciones (según afirmaciones del Marqués de Ureña, cit en Rico y Sinobas, ibid.) en los primeros años del XIX correspondía al modelo y firma de George Adams (hijo), dato que se ha confirmado en los inventarios de este centro, donde aparecen mencionados dos "barómetro y termómetro de J. Adams", Biblioteca e Instituto del Observatorio de la Marina (Cádiz), "Inventario general de los instrumentos que pertenecen al Observatorio Real de la Marina de Cádiz, sacado del original que ha sido formado en esta fecha. Cádiz, 11 de febrero de 1789 ".

53 Sobre este tema, M. SELLES, "Antonio de Ulloa y la ciencia de su época", en II Centenario de Don Antonio de Ulloa, Sevilla, 1995, pp. 59-77; espec. 66-73. Reiteramos aquí, como ya se indicó en la introducción, que en este contexto, relacionado con los estudios de geografía física, 


\section{La fabricación del barómetro: técnica y centros de producción}

De forma paralela a la práctica del barómetro, en España se llevaron a cabo diversos trabajos destinados a la adaptación de este instrumento a los usos meteorológicos que pretendían promoverse. De esta manera se iniciaba en el país un interés que ya contaba en otros lugares europeos con diversos precedentes. Es cierto que, en el resto de Europa, el motivo que condujo a su perfeccionamiento fue su ajuste al uso hipsométrico y a las consiguientes demandas de precisión. Pero el barómetro meteorológico, como ya se comentó, sólo debía cumplir unas mínimas condiciones. Precisamente es en este aspecto en el que destacan las propuestas españolas, y ya más particularmente, las que realiza el más representativo en este terreno: el ya nombrado Salvá. Junto a estos propósitos, a partir de la segunda mitad se detectan signos de una relativa producción nacional de barómetros, cuya finalidad predominante debía ser el gran público; sólo en casos excepcionales se atendieron los intereses científicos asociados con la meteorologí. Paralelamente se emprendieron labores de difusión del utillaje normalmente vinculado con estas ciencias de la atmósfera, cuyo objetivo, como se comprobará, era la promoción de la industria nacional. Aquí el personaje central es Alcalá Galiano.

Sobre la instrumentación meteorológica, Salvá leyó tres memorias ante la Academia de Ciencias y Artes de Barcelona, a la que pertenece desde 1786. Dos de ellas versaban sobre el barómetro ${ }^{54}$ : "Memoria sobre la construccion de instrumentos meteorológicos y especialmente del barómetro" ${ }^{55}$, de 1790 , y «Disertacion sobre el barometro portatil ${ }^{56}$, de 1792.

cabe incluir las labores relativas al análisis del territorio peninsular, como las del naturalista irlandés G. Bowles (Introducción a la historia natural y a la geografla fisica de España, 1775), o las correspondientes a las expediciones a América (como la de A. Mutis), donde el barómetro debía ocupar un lugar central, tanto en la determinación de la elevación de montañas como en las descripciones del estado atmosférico de localidades y regiones; sobre la actividad de los geógrafos españoles, H. CAPEL, Geografia y matemáticas en la España del siglo XVIII, Barcelona: Oikos Tau, 1982 y "Geograffa y cartograffa", en M. SELLÉs et al (comps.), Carlos III y la ciencia de la Ilustración, Madrid: Alianza, 1988, pp. 99-126. Este tema se tratará en futuros trabajos.

54 La tercera, ya mencionada, es «Memoria sobre higrómetrosm, de 1807

55 Archivo de la Real Academia de Ciencias y Artes de Barcelona (ARACAB), 13 de enero de 1790 , caja 16.

${ }^{56}$ ARACAB, 28 de marzo de 1792, caja 18. 
En realidad, la primera está centrada enteramente en el barómetro. Al principio ya cita a quien le acompaña en las labores de ejecución de los instrumentos, el artesano José Valls, maestro vidriero, orientado a las tareas relativas al utillaje científico gracias a su asociación con la Academia y con Salvá. Ingresó en el centro como académico artista en 1789 , momento en el que presentó dos termómetros que "eran los primeros que se habían construido en esta ciudad" ${ }^{57}$. Junto a estos instrumentos inició ese mismo ańo la fabricación de un barómetro portátil, tema que constituye el meollo de las reflexiones de Salvá. Definitivamente un año después se dedicaba enteramente a los instrumentos de meteoro$\operatorname{logí}^{58}$. La incorporación de Valls a la Academia representa un hecho doblemente significativo: primero, porque pone de manifiesto el interés de los académicos por la promoción de la incipiente industria de material cientifico ${ }^{59}$; en segundo lugar, porque se reconocía la aportación en los ambientes académicos de personajes procedentes del mundo artesanal, algo inusual en la época, que se había llevado a cabo por ejemplo en la Royal Society londinense, cuando se admitieron a individuos como J. y P. Dollond o J. Ramsden.

Salvá, en este primera memoria, señala los a su juicio principales aspectos técnicos a tener en cuenta en la fabricación de barómetros "buenos y perfectos". Así, se mencionan las dimensiones del tubo, cuyas paredes no deben exceder media línea y cuyo diámetro sea uniforme y que tenga al menos 263 líneas, así como que el tubo se encuentre limpio. Con respecto al mercurio, éste debe previamente destilarse ${ }^{60}$ y es esencial extraer el aire tanto de las paredes internas del tubo como del líquido. Por último, han de estar colocados adecuadamente y además estar convenientemente graduados ${ }^{61}$.

57 Noticia 1905-1906", ARACAB, "Expediente J. Valls".

${ }^{58} \mathrm{El}$ anuncio insertado en la Gaceta de Madrid (1790, N.० 10, p. 78) decía: "Los aficionados a la meteorología que deseen surtirse de instrumentos meteorológicos exactos, acudan a casa del mencionado Joseph Valls en la plazuela del Call de Barcelona, donde hallarán termómetros de azogue con la escala de Reaumur y la de Faherenheit, barómetros simples, o con termómetros, y barómetros portátiles de nueva invención, tan perfectos como los mejores extranjeros, y a precios más equitativos".

59 Sobre la industria de material científico en Barcelona, C. PUIG-PLA, "Màquines i instruments cientifics a l'Acadèmia de Ciències Naturals i Arts de Barcelona (1764-1824), en Actes de las $V$ Trobades d'Història de la Ciéncia i de la Tecnica, Barcelona: Societat Catalana d'Historia de la Ciència i de la Tècnica, 2000; en general sobre España, V. GUIJARRo, La ciencia ilustrada y sus máquinas, Madrid: UNED, 2002, pp. 175-189.

${ }^{60}$ En concreto, se refiere a que deben estar revivificados del «cinabar", proceso de obtención de mercurio por destilación que se conocía desde hacía tiempo.

6I "Memoria..", 1790, ARACAB, ff. 2-3. 
Posteriormente analiza uno a uno estos elementos básicos de la fabricación. Se extiende el médico barcelonés, por ejemplo, en un procedimiento de su invención, según confiesa más adelante, para comprobar que el diámetro interno es uniforme. Para ello se emplea una barra fina de hierro o plata, graduada en pulgadas, que se introduce en el tubo, maniobra que provoca el ascenso del mercurio. Seguidamente se retira poco a poco la barra, haciendo coincidir el nivel del mercurio con cada una de las graduaciones; se señalan en el tubo estas coincidencias y finalmente se miden para comprobar si son iguales ${ }^{62}$. En los comentarios del resto de los aspectos enumerados se encuentran las instrucciones para las operaciones de extracción del aire del mercurio y del tubo, problema ya apuntado al principio, cuya resolución en la segunda década del siglo significó la entrada en una nueva fase de la historia del barómetro. Pero igualmente destacable es el carácter empírico y escasamente predecible de las diferentes labores que debían llevarse a cabo para el fin mencionado ${ }^{63}$.

Una vez que tenemos el tubo con la correspondiente cantidad de mercurio se dispone sobre una tabla. El siguiente paso es el de la graduación. Para su ejecución se miden 27 pulgadas desde el nivel del mercurio en la "bola" (forma del depósito en un barómetro de sifón) hacia arriba. Estos puntos sirven de referencia para disponer una regla ${ }^{64}$ y en la parte superior una planchuela corrediza (el nonius), que tiene señaladas dos pulgadas con sus correspondientes líneas. Especialmente llamativo en este punto es el sistema que propone para evitar en las mediciones el efecto de paralaje. Consiste, según describe, en el uso del dedo índice, dispuesto en la parte superior del mercurio, y en la observación de la sombra proyectada por este sobre el vidrio ${ }^{65}$.

62 "Memoria...", 1790, ARACAB, ff. 3-5.

63 "La operación de limpiar los barometros, 6 purgarlos del aire por medio del fuego, se aprende mejor con la practica, que con todas las explicaciones. A puro romper tubos, y derramar azogue se sale Maestro, y en siendolo, rara vez se rompen, aun quando sean de vidrio verde ordinario, con tal que sus paredes no tengan mas de media linea de grueso, como queda dicho", ibid, f. 7.

${ }^{64}$ Se supone, por la época, que debía ser metálica, no de papel, si bien no se incluye en los detalles de coste del aparato que se presentan más adelante.

${ }^{65}$ "Para conocer que el ojo esta á nivel, se acerca el dedo indice a la parte superior del mercurio, y se levanta la cabeza, hasta que se vea la sombra, que el dedo hace en el vidrio, 6 cristal. Entonces se baxa la cabeza paulatinamente hasta desaparecer dicha sombra, y en aquel instante la vista se encuentra á nivel’, ibid., f. 10. 
Termina esta primera parte práctica con una alusión al precio de los instrumentos, asunto no carente de interés, e incluso determinante, porque era el que condicionaba la adquisición de estos útiles (recordemos que en el anuncio de Valls este es uno de los aspectos sobre los que se pretende llamar la atención). Según los cálculos de Salvá referidos a los elementos que componen el instrumento:

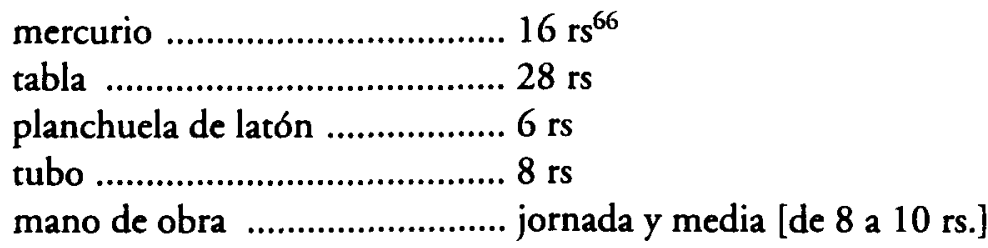

La segunda parte, la dedicada a la teoría, está destinada a proporcionar una justificación científica de las labores prácticas comentadas:

No basta haber dado las mejores reglas, que alcanzo, para construir barometros exactos, y cuias observaciones sean comparables con las que se hicieron con otros, sino se añaden los fundamentos en que se apoian dichas reglas ${ }^{67}$

Explica en esta sección las razones de la preferencia por los diámetros aconsejados de los tubos, y en el desarrollo de los argumentos muestra estar familiarizado con publicaciones foráneas sobre estos temas, especialmente las del citado Jean André de Luc y las de la Sociedad Meteorológica de Manheim. Del primero acepta sus conclusiones sobre los asuntos aquí tratados, como én el caso de la influencia de la temperatura en la variación de la columna ${ }^{68}$ ("como se necesita algunas veces, y con especialidad, quando se destina á medir la altura de alguna montaña $\left.{ }^{69}\right)$. En el resto, ofrece algunas razones sobre la necesidad de extraer el aire así como del sistema de comprobación de la uniformidad del tubo ideada

${ }^{66}$ Se ofrecen algunos datos comparativos: en 1785 , una barra de pan ( $950 \mathrm{gr}$ ) costaba 1,10 rs; en 1795, 1,37 rs.; el sueldo del catedrático de físca experimental de los Reales Estudios de San Isidro de Madrid era de 11.000 rs anuales.

${ }^{67}$ Ibid., f. 11.

${ }^{68}$ De Luc estableció como regla, para llevar a cabo la oportuna corrección, la relación de un grado en el termómetro igual a $1 / 16$ de línea del barómetro.

${ }^{69}$ Ibid, f. 13. 
por él. Cierra la memoria, dedicada especialmente a los barómetros más corrientes, cuestionando la precisión de los pies de rey manejados habitualmente, prefiriendo para los trabajos anteriores los del Real Colegio de Artillería de Segovia.

Si la primera memoria está destinada a los que allí se consideran como barómetros comunes, empleados en las determinaciones propias de las efemérides meteorológicas, esta segunda, de 1792, está centrada en los barómetros portátiles. Pero aquí "portátil» no significa que esté diseñado para su uso en el cálculo hipsométrico, como erróneamente se ha apuntado ${ }^{70}$, sino, como se señala al final de la memoria, para evitar los problemas que acompañan a su transporte de un lugar a otro, donde se empleará como fijo para las pertinentes observaciones. Así, dice el autor al final:

Me hago cargo que el armar y desarmar mi barometro es mucho mas penoso, que el montar o desmontar el del sobredicho Autor [Ramsden], y de otros hechos por un termino semejante; de suerte que seria muy engorroso el hacer observaciones con el en las montañas; en la quales faltan mesas y a menudo planos, en que poderlo poner orizontal; pero sobre que mi fin fue solamente el de poderlos enviar a varios Fisicos del Reyno que quieran hacer observaciones en sus casas; dire que si con mi barometro puede uno asegurarse luego de su buen o real estado, lo que es mas largo en los otros, si es mas facil de remediar el defecto, que hubiere adquirido en el camino, que en los otros; por fin si aquel no esta tan expuesto a desvaratarse como estos importa poco el mayor trabaxo de montarlo. Los barometros que se han enviado a Altafu$1 a^{71}$, Mallorca, Menorca, y hasta a Buenos Ayres han llegado completamente bien; y discurro que mientras se remitiesen con mulos de carga, y no en carruage, no se desvaratarian tampoco, aunque se enviasen a Madrid ${ }^{72}$.

${ }^{70}$ V. J. VERNET, Historia de la ciencia española, Barcelona: Alta Fulla, 1998 (facs. ed. 1975), p. 175.

${ }^{71}$ Localidad de nacimiento de Antonio de Martí y Franqués (1750-1832), ạmigo de Salvá y dedicado a las investigaciones químicas de la atmósfera e interesado en las observaciones meteorológicas, que llevaba a cabo regularmente en esta localidad de Tarragona, donde poseía haciendas; sobre este autor, J. M. L. PINERO et al., Diccionario histórico de la ciencia moderna, Barcelona: Península, 1983, vol. II, pp. 25-27.

72 "Disertacion sobre el barometro portatil", 1792, ARACAB, caja 18, ff. 14-15; así mismo: "Me ha parecido dar a V.E. de los mas principales [características de los barómetros más importantes] antes de explicar los que idee, en los quales no mire tanto el que pudiese viajarse con ellos hasta los montes mas encumbrados, como que nuestro compañero Dn Josef Valls pudiese remitirlos a varios sugetos del Reyno que deseen hacer experiencias con el barometro», ibid., f. 5 . 
Más bien considero que la presente memoria es un complemento de la primera, la de 1790. Aquí, el asunto central es, pues, la descripción de un método para que en el transporte se resolviera el problema, ya señalado al comienzo, de que se rompiera el vidrio por los movimientos internos del mercurio. Previamente, sin embargo, hace una breve reflexión sobre el precio de los barómetros y sobre las características de otros modelos, especialmente el de de Luc. Como ya se indicó anteriormente, la cuestión económica no era en absoluto irrelevante. Salvá pretende en este punto manifestar su disconformidad con el desinterés generalizado por la adquisición de barómetros de los proveedores nacionales, teniendo en cuenta que su coste es notablemente inferior al de los extranjeros ${ }^{73}$ :

Debemos lamentarnos, de que quando en otros paises no se tiene por caro este instrumento sencillo, quando cuesta diez o doce pesos [ 160 ó 192 rs], se juzga acá que cinco duros [90 rs], que lleva por ellos el Sr Valls, es un precio exorbitante. Por este motivo fue preciso hacer egecutar los portatiles de modo, que su valor excediese muy poco de los regulares. Tenemos aun muy pocos sugetos, que quieran gastar doce, y aun veinte y cinco doblones en un barometro portatil [ $1500 \mathrm{rs}$ ] que es el precio á que se han vendido algunos de los que se han ideado en otros Reynos.

El caso aquí comentado nos remite a un problema más general que tiene que ver con el desarrollo de la industria nacional de instrumentación científica y su consolidación. Esta comenzó tímidamente a dar sus primeros pasos a partir de mediados del s. XVIII, coincidiendo a su vez con los inicios de la modernización científica y de su canalización a través de la creación de nuevas instituciones. En esos momentos aparecen los primeros anuncios de negocios que tienen que ver con la fabricación, venta o distribución de utillaje científico y demostrativo en lugares que contaran con centros educativos o dedicados parcial o completamente a la investigación, donde destacan, dado el centralismo borbónico dominante, los establecimientos de Madrid. También por esa época comienzan a llegar constructores procedentes de otros países para el mantenimiento de colecciones o la realización de nuevas piezas. En el caso concreto de la barometría fue contratado A. Mossy, quien, procedente de Francia, debía hacerse cargo de la colección recientemente adquirida por el Seminario de Nobles en 1750,

${ }^{73}$ Ibid., ff. 5-6. 
llegando a tener el título de "barometrista de S.M. ${ }^{74}$. De este fabricante se conserva un barómetro de sifón en el Museo Nacional de Ciencia y Tecnología ${ }^{75}$, cuya factura no contiene elementos destacables ${ }^{76}$.

Por esta época, sin embargo, el centro más importante dedicado a la instrumentación científca en España, si bien con un destino demostrativo y para el recreo popular (aunque también contaba con encargos particulares de profesores $^{77}$ ), era la Real Fábrica de Cristales, en concreto su sección dedicada a las piezas de óptica establecida en 1746 en Madrid, en la carrera de S. Francisco. Fueron contratados con el cargo de maestros los especialistas franceses Diego Naigeon y Juan Bautista Marie, quienes deberían encargarse de la fabricación de todo tipo de lentes para la vista y para la instrumentación científica (telescopios, microscopios y máquinas eléctricas), así como de otras piezas que incluyeran vidrio, como los tubos barométricos. Los documentos con referencias a este último tipo de piezas indican una producción anual significativa. (Tabla 1).

Su estancia se prolongó hasta 1753, momento en el que se hace cargo de la sección Domingo Núnez, pero sólo hasta 1758. A partir de esta etapa comienza una decadencia significativa de las Manufacturas: primero se decide, ignorándose su razón, su traslado a Segovia; segundo, los aprendices formados

74 Se encuentra esta consideración en los documentos correspondientes a la Fábrica de Cristales de S. Ildefonso (Sala de óptica, Madrid), en Archivo de Palacio, Real Fábrica de Cristales, "Almacén de Madrid", caja 608, "Piezas realizadas" [1753].

${ }^{75}$ Museo Nacional de Ciencia y Tecnología, No 85/4/13, con la inscricpción "Antonius Mossi/ Ft. Año 1760m. El hecho de que se encuentre en este fondo procedente de los antiguos Reales Estudios de San Isidro, que a su vez hereda las piezas del Colegio Imperial, sugiere que posiblemente también trabajó para esta última institución; de hecho M. Lanz de Casafonda (Dialogos de Chindulza, 1761, ed. de F. Aguilar Pinal, Oviedo, Universidad, 1972, p. 65) dice, referiéndose al Colegio Imperial, que use trajeron de Londres a expensas también del Rey diferentes instrumentos matemáticos, que importaron sumas inmensas (sólo el cuadrante inglés costó cinco mil pesos), se hizo un grande observatorio, se pusieron con 5 reales diarios un portero y barrendero, y un barometrero con 100 doblones y casa al añon.

${ }^{76}$ En realidad, por la escasa información existente, pensamos que llegó a Espańa después de un período breve de aprendizaje en Francia; su etapa de madurez la alcanzaría sin embargo en el país galo, una vez que volvió en torno a 1765, llegando a conseguir una cierta fama como fabricante de termómetros y barómetros de precisión; sobre Mossy, W. E. K. MIDDLETON, The History of the Barometer, opus cit, pp. 89-90 y 199, y "Apendix", Ns. 1578, 1579, 1582, 1583 y 19948; del mismo autor, $A$ History of the Termometer, Baltimore: The John Hopkins Press, 1966 , p. 119.

${ }_{77}$ Por ejemplo, de J. Wendlingen, profesor de matemáticas del Colegio Imperial. 


\begin{tabular}{|c|c|}
\hline Año & Producción \\
\hline 1749 & $\begin{array}{l}\text { Referencia a "cristal matemático" y "botellas", } \\
\text { destinadas probablemente a la confección de ba- } \\
\text { rómetros }{ }^{78} \text {. } \\
16 \text { botellas de cristal que sirven al barómetro }{ }^{79} \text {. }\end{array}$ \\
\hline 1751 & $\begin{array}{l}\text { Referencia a "barómetros delgados, barómetros } \\
\text { gruesos... }{ }^{80} \text { (no se especifica cantidad) }\end{array}$ \\
\hline 1752 & $\begin{array}{l}\text { Referencia a } 300 \text { "barómetros a } 3 \text { quartos", y } \\
395 \text { "barómetros a } 6 \text { quartos" }{ }^{81} \text {. }\end{array}$ \\
\hline 1753 & 32 “cañoncitos para barómetros»" \\
\hline 1755 & 77 "cañas o tubos de barómetro" ${ }^{83}$ \\
\hline
\end{tabular}

Tabla 1

en el centro se niegan a acompañar el destino de su taller y establecen por su cuenta negocios en Madrid, representando de esta manera una seria competencia para los productos procedentes de las Manufacturas Reales. Aunque se volviera a abrir seis ańos después, hasta aproximadamente 1780 no recuperó su actividad normal. En esta segunda etapa destaca la contratación como profesor de instrumentos matemáticos y ópticos del francés P. Mégnié, el "fabricante preferido de Lavoisier ${ }^{84}$, quien, entre otras piezas, estaba familiarizado con la teoría y construcción de los barómetros ${ }^{85}$. Pero, además, en esta fase, que coincide con el traslado de la sección de óptica a la calle del Turco en 1790 , se establece a cargo de Megnié, junto a las dependencias dedicadas a la

${ }^{78}$ AP, RFC, ibid, caja 612, Leg. 31, "Piezas matemáticas»; sobre el origen y evolución de la sala de óptica durante el período considerado, Paloma PASTOR ReY DE VINAS, Historia de la Real Fábrica de San Ildefonso durante la época de la Ilustración (1727-1810), Madrid, Fundación Nacional del Vidrio, 1994, pp. 168-180.

${ }^{79}$ AP, RFC, ibid., caja 613, "Cristales labrados mandados entegar por órdenes particulares, 1749-1750m.

${ }^{80}$ Ibid, caja 615, 1751.

${ }^{81}$ Ibid, caja 608, 1752.

82 Ibid., caja 610, 1753.

${ }^{83}$ Ibid., caja 653., Expte 1, Carta de 30 de agosto de 1755.

${ }^{84}$ MIDDLETON, The History of the Barometer, opus cit., p. 139, n. 20; sobre este fabricante existe una cietta confusión ya que hasta 1786 , año de su traslado a Madrid, no distingue sus trabajos de los de un hermano o pariente (Mégnié el joven, que posteriormente también colaboraría con Lavoisier), véase DAUMAS, opus cit., 360-363.

${ }^{85}$ Véase MidDleton, ibid., pp. 250 y 459. 
elaboración de objetos, un "taller de instrumentos de astronomía, con todas sus dependencias anexas, destinadas a diferentes usos: Sala de lecciones, Observatorio Astronómico y Obradores...1 ${ }^{86}$. Con alta probabilidad, a estas clases asistieron, entre otros, el ya mencionado Garriga, futuro profesor de Meteorología del Real Observatorio Astronómico de Madrid ${ }^{87}$.

Junto al conocimiento de la teoría de la fabricación y uso del barómetro, en España estaba asegurada su construcción. Además de los procedentes de las manufacturas madrileñas, de manera independiente existían negocios dedicados a estas labores, como el de J. Cosa ${ }^{88}$, asociado desde 1786 con A. Lera; su oferta comprendía barómetros, termómetros, máquinas eléctricas y pneumáticas y microscopios ${ }^{89}$. A estos, finalmente, hay que sumar quienes, como D. Rostriaga, estaban al cargo de colecciones de centros y estaban capacitados para la realización de este tipo de artefactos; por ejemplo, su sobrino, C. Rostriaga, su ayudante en los Reales Estudios de S. Isidro en Madrid, llegó a fabricar diversos barómetros, de los que se conservan actualmente tres ejemplares ${ }^{90}$.

El barómetro, pues, había alcanzado un alto grado de difusión en España. Sin embargo, el único caso conocido de dedicación exclusiva a los instrumentos meteorológicos es el de J. Valls. Pero las razones que movieron a Salvá a reclamar la atención sobre este fabricante estaban relacionadas - pienso- con el intento frustrado de participación en el proyecto meteorológico internacional promovido por la Sociedad Meteorológica Palatina, derivado de incidentes acontecidos pocos ańos antes de la adscripción del artesano a la Academia. En 1786, el conde de Floridablanca informaba a la Academia de Barcelona del envío a este centro de un grupo de instrumentos meteorológicos adquiridos en el extranjero (esto

${ }^{86}$ P. PASTOR, opus cit., p. 340.

${ }^{87}$ Además de la obra citada anterioremnte es autor de Uranografia o descripción del cielo; sobre su vinculación al observatorio, J. TINOCO, Apuntes para la historia del Observatorio de Madrid, Madrid, 1951, pp. 13-16.

${ }^{88}$ Precisamente Alcalá Galiano le había enseñado la técnica de fabricación de termómetros y barómetros según los principios de de Luc, Mem. Lit., diciembre de 1786, p. 462.

${ }^{89}$ Gaceta de Madrid, N.o 87, 29 de octubre de 1784, y N.० 8, 17 de enero de 1786.

90 Un barómetro de 1796 (en Palacio de Aranjuez, No 52848), uno de 1798 (Palacio de Riofrío, N.0 60679) y un tercero, provisto de termómetro, también de 1798 (Palacio de Aranjuez, No 23964). 
es, procedentes de Mannheim), instrumentos que se encontraban en la Secretaría de Estado, en Madrid ${ }^{91}$. Pero cuando J. Bonells se traslada a la capital para recoger las cajas con el material descubre que la del utillaje meteorológico se había entregado al "Colegio de Nobles" (Seminario de Nobles) y que la reservada a la Academia sólo contenía «un declinatorio o maquina para medir la declinacion de la aguja", una "Historia y Efemerides meteorologicas de la Sociedad Palatina" y un tratado sobre los pararrayos ${ }^{22}$. Después de las oportunas reclamaciones y viéndose además forzados a devolver la caja que ellos mismos poseían, en la Academia se decidió en diciembre de 1787 pedir un segundo juego a Mannheim, solicitud desatendida debido a la existencia de un observatorio muy próximo, en la ciudad de Marsella ${ }^{93}$. Un año y medio después, una vez que se había mostrado el interés de la Academia por las observaciones meteorológicas ${ }^{94}$, era admitido en esta institución Valls.

No existen evidencias acerca de que este material se emplease para usos científicos en el seno del Seminario de Nobles de Madrid. Lo que sí conocemos son las características del barómetro que llegó a España a partir de la figura que aparece en uno de los trabajos sobre la Sociedad Palatina ${ }^{95}$ (véase la figura). Este contiene una escala graduada entre las 25 y las 29 pulgadas; cada una de éstas se divide a su vez en 12 líneas. Además está provisto de una placa corrediza, el nonius, con 10 divisiones, la cual presenta la particularidad de tener un apéndice curvado (el indicador) cuya finalidad es adaptarse a la convexidad de la superficie del mercurio. Es decir, la sensibilidad de los instrumentos era de $1 / 10$ de línea (o 1/120 de pulgada), niveles máximos en los que se desarrollan las medidas que aperecen en los diarios meteorológicos españoles, como se vio anteriormente.

Salvá tenía pues motivos para expresar sus quejas. Algunas decisiones, como las de Campomanes y Floridablanca, no contribuyeron al despegue de algunos negocios independientes ni a un principio de consolidación de la industria de instru-

91 "Diario de Juntas, 6 de diciembre de 1786", en J. Iglesies Fort, "La Real Academia de Ciencias Naturales y Artes de Barcelona", Memorias de la Real Academia de Ciencia y Artes de Barcelona, 36 (1964): p. 527.

92 "Diario de Juntas, 22 de enero de 1787" y "Diario de Juntas, 8 de febrero de 1787" en ibid, pp. 529 y 531 .

${ }_{93}$ Ibid., pp. 532, 536-7 y 541 .

94 "Diario de Juntas, 4 de febrero de 1789 ", ibid., 553.

${ }^{95}$ KINGTON, opus cit, p. 417. 


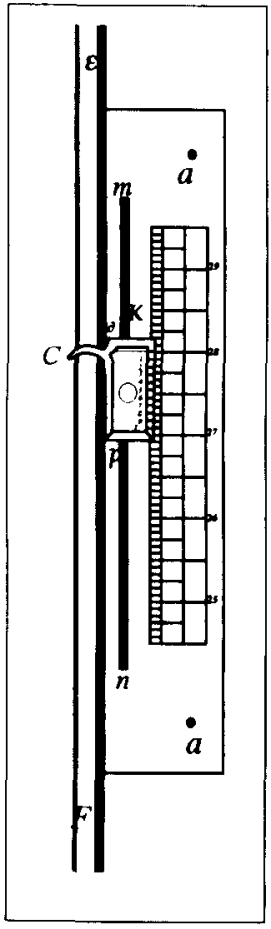

mentos en España, en la que, como ocurrió en otros países, sólo por la atención a estos grandes proyectos (geográficos, marítimos y meteorológicos) podía lograrse el ansiado desarrollo, reclamado insistentemente desde 1775 por diversos autores.

Volviendo a la memoria de Salvá, en las siguientes páginas se centra en algunos inconvenientes del modelo de de Luc que desaconsejan su distribución, fuera del manejo del propio autor, para llevar a cabo las tareas asociadas con un barómetro portátil. Una alternativa a este diseño eran, según el médico barcelonés, las ideas tanto de Ramsden como de Magellan, descritas en los "Diarios de Física de París». Después de consultar las referencias proporcionadas por el propio Salvá ${ }^{96}$, en el primer caso se comprueba que no es en realidad un modelo de Ramsden, sino de A. Perica, ingeniero francés del Rey para instrumentos de física en vidrio. Se trata eso sí de un barómetro transportable, con cisterna ajustable para mantener el nivel 0 y para llenar la cavidad cuando fuera necesario proceder a un cambio de lugar. En el segundo caso, el de Magellan, sí pertenece a una propuesta del polifacético portugués ${ }^{97}$, cuyo barómetro está ideado para medir alturas de montañas y que, según el autor, presenta, ahora sí, algunas similitudes con los pertenecientes al fabricante inglés ${ }^{98}$.

Para Salvá, básicamente la propuesta de estos autores consistía en disponer un receptáculo flexible en la cisterna, que pudiese contraerse y expandirse por medio de un mecanismo manipulado externamente; de esta forma el mercurio que se encontraba en su interior podía comprimirse, evitando asl su agitación en el transporte. Pero tampoco esta construcción estaba libre de dificultades, ya sean debidas a los efectos del frío y el calor que provocaban la creación de espa-

96 "Diarios de Física", t. 18, p. 393, que corresponden al artículo de A. PERICA, "Description d'un baromètre a surface plane perfectionné», Journal de Physique, 18 (1781): 391-394.

${ }^{97}$ J. DE MAGELLAN, “Baromètre nouveau", Journal de Physique, 19 (1782): 108-125.

${ }^{98}$ La tercera referencia proporcionada por Salvá corresponde a un trabajo de J. H. HURTER, "Lettre a M. De la Matherie, contenant la description d'un nouveau Baromètre portaif plus simple, plus parfait \& moins susceptible d'accidens, que tous les autres faits précedement", Journal de Physique, 29 (1786): 346-349. Aquí se critica el modelo de Ramsden mientras se elogia el de de Luc. 
cios en el receptáculo, o a la posición —invertida - que debía adoptar para su transporte, lo cual podía generar pequeñas ampollas de aire que ascendiesen hasta el lugar que se suponía estaba vacío ${ }^{99}$. La idea de Salvá para superar estos obstáculos era la de diseñar un barómetro cuya parte inferior, la correspondiente a la cisterna, pudiese separarse formando un cuerpo independiente del tubo. Ambas piezas se transportarían de esta forma hasta el lugar de destino y alli se unirían siguiendo las instrucciones que detalla el autor en su "Instructa para armar el Barometro portatil». Los problemas ahora estaban relacionados con el engorro de tener que armar y desarmar en cada desplazamiento el instrumento, hecho que lo hacía inviable, como ya se había señalado anteriormente, para su empleo en la medición de montañas.

La desatención a los elementos que tuvieran que ver con la sensibilidad y la precisión del instrumento, o bien la ausencia de referencias a determinaciones cuantitativas o a piezas adicionales como el nonius, indican la intención del autor: frente a los modelos de de Luc, Ramsden y Magellan, la aspiración de Salvá tanto en la memoria anterior como en esta es describir y proveer barómetros que simplemente funcionen correctamente. Poco más debía demandarse de este tipo de instrumentos, teniendo en cuenta la finalidad y el marco en el que se inserta su uso, que no es otro que el de las observaciones meteorológicas tal y como son concebidas por el autor.

Salvá, según se ha visto, emprendió algunas reflexiones sobre la fabricación del barómetro con la intención de adaptar este instrumento a las que para él representaban las finalidades más convenientes, es decir, a la confección de diarios meteorológicos cuya condición previa era la disposición de una red de observadores, haciéndose eco así de proyectos similares emprendidos en diversas ciudades europeas. Sus comentarios, desprovistos de alcance teórico y reducidos a la pretensión de mostrar algunos consejos útiles para su fabricación, cuentan en España con tan pocos precursores como seguidores. En el primer apartado ocupa este lugar con exclusividad Alcalá Galiano. Es autor de la «Memoria sobre la Construcción y Uso de los Instrumentos Meteorológicos", de 1783, que sólo recientemente ha sido publicada ${ }^{100}$. Enviada a la Sociedad Económica Matriten-

99 "Disertacion sobre el barometro portatil", 1792, ARACAB, caja 18, ff. 9-10.

${ }^{100}$ En J. L. GARCfa HourCADE, La meteorologia en la España ilustrada y la obra de Vicente Alcalá Galiano, Segovia: Asociación Cultural "Biblioteca de Ciencia y Artillería", 2002. 
se en ese ańo, este trabajo, casi con seguridad el primero de estas características elaborado en la península, está dedicado al termómetro, barómetro, higrómetro, anemómetro, udómetro (pluviómetro), brújula y electrómetro. Atendiendo solamente al barómetro, las líneas en las que se ocupa de este instrumento están pensadas, como en el resto de las piezas, para difundir el conocimiento de su fabricación ${ }^{101}$ y estaba dirigido a quienes tenían "principios de buena Física» ${ }^{102}$, es decir, pienso que a los constructores cuya formación comprendiese conceptos de mecánica práctica y probablemente de física experimental ${ }^{103}$.

Trata diversos asuntos en esta memoria, donde destaca la presencia recurrente de las conclusiones de de Luc, referencias que junto con las ya vistas de Salvá (quien le cuestiona tímidamente) sitúan al físico francés entre los más influyentes en la barometría de nuestro país. Primero, el autor describe las operaciones básicas así como las precauciones que deben tenerse en cuenta en la elaboración de los barómetros en general. Destaca aquí, por ejemplo, el comentario sobre la escala, dividida en líneas, cuartos de línea y éstas a su vez divididas en cuatro partes (lo que permite disponer de una sensibilidad de 1/16 de línea, como corresponde también a los instrumentos de de Luc). En un segundo grupo de cuestiones, de mayor interés para los temas que se discuten en este artículo, se centra ya de manera específica en los "barómetros que deben servir para las observaciones meteorológicas». El instrumento, según esta sección, se emplea para la previsión del tiempo, para determinar cuál es su mayor y menor elevación según el clima, y tercero, para comparar los resultados medios, máximos y mínimos con otros lugares. Para las dos primeras finalidades no es necesario tanto exactitud como "escrupulosidad»; para la última sí es preciso que los barómetros sean comparables $^{104}$. Así pues, en las líneas que siguen describe los pasos que han de seguirse para lograr este fin. Es digno de mención, finalmente, la colección de reglas meteorológicas, en total 16, complementadas con algunas indicaciones posteriores,

${ }^{101}$ En el prólogo dice: "Como uno de mis primeros fines ha sido el que se conozca y extienda en nuestra Espana el método de construir semejantes Instrumentos, he procurado no omitir ninguna cosa de cuantas me han parecido necesarias y convenientes para su mejor construcción...", en ibid., p. 173.

102 Ibid., p. 174.

${ }^{103}$ Los tratados de física experimental contenían amplia información sobre instrumentación cientifica, y en particular sobre el barómetro y su uso; sobre esta disciplina y su alcance en el siglo XVIII, V. GUIJARRO, "Petrus van Musschenbroek y la física experimental del siglo XVIII", Asclepio, 53 (2001): 191-212.

${ }^{104}$ Ibid., p. 209. 
que indican el estado en el que se encontraba la ciencia de los estudios atmosféricos. Todavía en este período se mantenía que la incertidumbre en la previsión de las mutaciones de la atmósfera se derivaba de la imperfección de los instrumentos ${ }^{105}$, no de las insuficiencias teóricas.

En definitiva, Galiano, entusiasta de las observaciones meteorológicas, se limitaba a presentar de forma sintética y con una intención divulgativa los pormenores de la instrumentación característica de este ámbito con el fin exclusivo, pienso, de estimular el interés por su uso.

Finalmente, después de Salvá, leyó también ante la Academia un discurso sobre el barómetro F. Sanponts ${ }^{106}$. Era el responsable de las Direcciones de Matemáticas y Mecánica y anteriormente de la de Estática ${ }^{107}$ de este centro. Su única intención, como ya indica al comienzo del trabajo, es, más allá de las especulaciones acerca de las causas del ascenso o descenso del líquido o bien de sus aplicaciones en la previsión del tiempo o en el cálculo de la elevación de las montañas y altura de la atmósfera, "arreglar los barometros para que sean portatiles» ${ }^{108}$. Después de llamar la atención sobre la excelencia de los barómetros de Valls, siguiendo así las afirmaciones realizadas unos años antes por Salvá, pasa a exponer el verdadero motivo que anima la presentación de la memoria, que no es otro que el descubrimiento casual de un método que facilitaría las labores de transporte del instrumento evitando las engorrosas operaciones enumeradas por su colega académico. Es difícil concebir una idea de esta nueva propuesta a partir de las breves explicaciones de Sanponts exentas de ilustraciones. La clave en cualquier caso se reduce, según las indicaciones del autor, a un estrechamiento que presenta el tubo, el cual impide movimientos bruscos del mercurio y por tanto que éste rompa el vidrio ${ }^{109}$.

Para terminar, se hará una referencia a un barómetro conservado en el Museo Nacional de Ciencia y Tecnología de Madrid ${ }^{110}$ (véase las ilustraciones al final del artículo), procedente de la colección de piezas que pertenecieron a los antiguos Re-

${ }^{105}$ Ibid., p. 213.

106 "Discurso sobre los barómetros portatiles", 1796, ARACAB, caja 18

107 J. IGLESIES FONT, "La Real Academia....", pp. 219-22.

${ }^{108}$ SANPONTS, opus cit, f. 1.

${ }^{109}$ Ibid., ff. 7-8.

${ }^{110} \mathrm{No}$ inventario: 85/4/19. Las fotograffas aquí empleadas pertenecen al archivo fotográfico del Museo Nacional de Ciencia y Tecnología, centro al que agradezco las facilidades y apoyo prestados para acceder a este material. 
ales Estudios de San Isidro, que podría corresponder con el instrumento estándar empleado en los estudios meteorológicos de la época. Se trata de un barómetro de cubeta, de $94 \mathrm{~cm}$. de longitud, que presenta una escala dividida en dos partes: una graduación "española» de 26 a 34 pulgadas, y una graduación "francesa», de 23 a 29 pulgadas. La parte española está provista de una placa corrediza ${ }^{111}$ con las inscripciones "Muy seco/ Sereno/ Buen tiempo/ Variable /Lluvia /Gran lluvia/ Tempestad». La parte francesa contiene una placa móvil, el nonius, dividido en 10 partes y con una aguja para señalar el nivel alcanzado por el mercurio. Teniendo en cuenta las diferentes divisiones, la sensibilidad máxima era de 1/120 de pulgada.

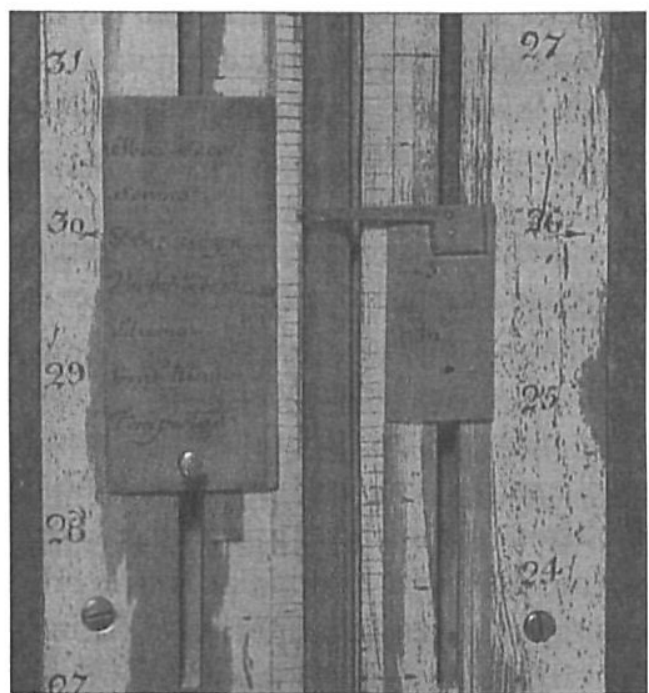

Detalle de la graduación y del nonius

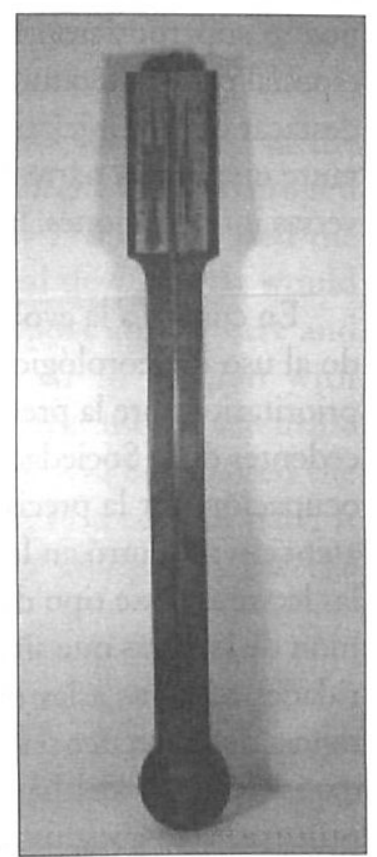

Barómetro de cubeta del Museo Nacional de Ciencia y Tecnología $(85 / 4 / 19)$

\section{Conclusiones}

España no llegó a disponer de una institución que contara con el liderazgo que demandaba el impulso y coordinación de un proyecto meteorológico de las carac-

${ }^{111}$ Para adaptarla a la altitud media del lugar de uso del instrumento. 
terísticas que adquirieron en otros países europeos, donde en cualquier caso también se requirió superar diversas dificultades para mantener con la regularidad necesaria estas labores, dependiendo su supervivencia de la voluntad y persistencia de unos pocos. La Academia de Barcelona se encontraba en la posición más ventajosa para haber asumido esa tarea, pero quizás debido a razones políticas de corte centralista no le fue concedido ese privilegio. Estos factores tendrían un efecto inmediato en el desarrollo de la instrumentación científica nacional, que no encontró en el entorno científico inmediato ni el interés ni la confianza precisas para justificar una producción especializada: la comunidad de profesores e investigadores prefirió seguir acudiendo a los talleres foráneos. En este caso, pues, los motivos externos se superpusieron a los técnicos, accesibles, dada además la familiaridad en especial con la literatura y utillaje franceses, a los artesanos españoles. Sólo hay que destacar que las iniciativas individuales sí conocieron una relativa continuidad durante una buena parte del s. XIX, como la de Salvá, la de Campomanes y, con diversas interrupciones, las de los observatorios astronómicos.

En cuanto a la evolución del barómetro, se ha comprobado que en el destinado al uso meteorológico la normalización (estandarización) era el criterio técnico prioritario sobre la precisión. No sólo en España, también en los barómetros procedentes de la Sociedad Meteorológica Palatina, como indica Middleton, la upreocupación por la precisión absoluta» era un elemento secundario ${ }^{12}$; más bien la atención se centró en la sencillez tanto en el manejo como en la interpretación de las lecturas. Este tipo de barómetros cumplieron una finalidad primordial: la reunión de lecturas que sirvieran al conocimiento del clima. Es decir, de las tres prioridades relativas a las observaciones meteorológicas señaladas por Salvá (la inferencia de la frecuencia e intensidad de las variaciones atmosféricas a partir de los datos, la teoría del barómetro y la predicción) sólo se cumplió relativamente la primera. Una conclusión a la que también se llegaría en el resto de los proyectos europeos, si bien estos contaron con una participación más amplia. En cualquier caso, teniendo en cuenta los pasos importantes que se habían dado, aún faltaban los elementos teóricos que definirán la meteorología del XIX, especialmente los relativos a los mapas provistos de isolíneas, los cuales podían proporcionar un patrón sintético ausente en los planteamientos ilustrados. 


\title{
EL USO DE INSTRUMENTOS CIENTÍFICOS EN LOS PRIMEROS VUELOS AEROSTÁTICOS TRIPULADOS
}

\author{
Juan Alberto Molina García \\ UNED
}

ABSTRACT: After the Montgolfier's invention of a hot-air balloon at the end of the $18^{\text {th }}$ century, the success of the first manned-flight in an hydrogen balloon by the french physicist Charles on 1 st december 1783, supposed the begining of a series of experiences on board of such aerial devices that would lead to a progresive knowledge of the behaviour of the upper atmosphere and to determine the variation of some properties of the air in relation with height. The purpose of this paper is to examine how the use of scientific instruments was decisive to obtain these results, so that it will be analised the work realised by some French balloonists in their rides; in a second part, it will be commented the work developed in Spain, to compare with the formerly mentioned.

\section{Introducción}

Navegación aerostática y experiencia científica se nutrieron mutuamente desde la aparición del primer globo, a finales del siglo XVIII ${ }^{1}$. La aerostación surgió gracias al concurso de varias ciencias ya consolidadas y a los novedosos avances en química neumática ${ }^{2}$; recíprocamente, la invención del globo aerostático fue un factor que contribuyó de forma decisiva al desarrollo de las investiga-

1 Sobre la invención del globo aerostático de aire caliente, los materiales empleados en su construcción y las primeras demostraciones públicas, puede consultarse GILLISPIE, Ch. C., The Montgolfier brothers and the invention of aviation, 1783-1784, Princeton University Press, 1983, capítulo I, pp. 3-25.

${ }^{2}$ Ibid., pp. 15-17. Véase también SCOTT, A., "La invención del globo aerostático y el nacimiento de la químican, Investigación y Ciencia, 91 (1984): 88-97. 
ciones sobre la atmósfera terrestre, composición química del aire, comportamiento de los organismos a diferentes alturas, etc ${ }^{3}$. El papel de los instrumentos científicos en la medición de variables atmosféricas, análisis de muestras de aire o estudio del magnetismo terrestre, era primordial; fue precisamente al comenzar los vuelos tripulados cuando se pudieron confirmar o mejorar determinadas teorías ya existentes ${ }^{4}$ y refutar otras ${ }^{5}$. Los estudios realizados requerían de un utillaje científico fiable y especializado, buena parte del cual ya gozaba de amplia aceptación entre los investigadores, así como de un alto grado de perfeccionamiento; por otra parte, la aparición de ciertas disciplinas experimentales, como la meteorología, tuvo su razón de ser en las mediciones sistemáticas efectuadas con aparatos adecuados, empresa que, como veremos, alcanzó un fuerte impulso gracias a los registros llevados a cabo por los primeros aeronautas. En este artículo repasaremos brevemente el uso que se dio a los instrumentos científicos como utensilios de navegación aérea, pero nos centraremos sobre todo en sus aplicaciones a la aerostación científica, para lo que tendremos en cuenta las experiencias de los aeronautas franceses y españoles como referencia principal. Comprobaremos que, frente a los trabajos más abundantes y sistemáticos de los primeros, escasearon los de los segundos, si bien a éstos no se les puede quitar mérito debido a que enseguida comprendieron la utilidad de los globos y de los instrumentos en la ciencia. Respecto a Francia, nos centraremos en dos casos paradigmáticos por la significativa y acertada aportación que se hizo a las indagaciones sobre determinados aspectos del comportamiento atmosférico y de la composición química del aire: nos referimos a sendos vuelos protagonizados por L. B. Guyton de Morveau y J. L. Gay-Lussac, que tuvieron lugar con veinte años de diferencia y de los que pondremos especial énfasis en los instrumentos que fueron llevados a bordo, el uso que se les dio y las conclusiones obtenidas. En cuanto a España, destacaremos la figura de V. Lunardi, aeronauta italiano que efectuó mediciones de la temperatura, presión y humedad desde un globo y que nos interesará especialmente por haber proporcionado al Real Laboratorio de Química de Madrid una muestra de aire atmosférico tomada en uno de sus vuelos para su posterior análisis; aunque sólo podamos mencionar este caso, no puede pasar desapercibido el hecho de que los autores espanoles que escribieron

${ }^{3}$ Para hacerse una primera idea sobre las aplicaciones cientificas y militares de los globos, puede consultarse FoURIER, J., "Éloge de Mr. Charles", Mémoires de l'Académie Royale des Sciences de France, 8 (1829): lxiii-lxxxviij.

${ }^{4}$ Disminución de la temperatura, presión y humedad del aire con la altura.

${ }^{5}$ Supuesta pérdida de la intensidad del magnetismo terrestre al alejarse de la superficie. 
sobre temas relacionados con la aerostación siempre hicieron justicia al valor de los aparatos en los viajes aerostáticos, bien porque fueran usados como instrumentos imprescindibles para la navegación aérea o bien porque su intervención en la investigación científica desde el aire fuese de suma importancia.

\section{Generalidades sobre aerostación científica en Europa}

Tras la invención del globo aerostático de aire caliente por los hermanos J. y E. Montgolfier, el físico francés J. A. C. Charles y el artesano parisino J. Robert realizaron un vuelo en el globo de hidrógeno de su invención que marcaría un momento decisivo en el futuro de la aerostación científica. Mediante un termómetro y un barómetro, los dos aeronautas pudieron registrar las modificaciones de la temperatura y de la presión atmosférica a medida que se elevaban. Este hecho era interesante por dos razones: $\left.1 .^{\circ}\right)$ la medición de dichas variables permitía controlar los cambios de volumen del saco del globo y operar en consecuencia para evitar posibles reventones del mismo, cosa que se pudo lograr gracias al manejo de la válvula y de la zona de rasgadura (ésta fue incorporada como medida de precaución en caso de emergencia), lo que facilitaba a su vez el dominio del ascenso y del descenso del globo a voluntad del piloto; $\left.2 .^{\circ}\right)$ se podía establecer una correlación entre dichas modificaciones y la altura alcanzada para lograr un mejor conocimiento de la atmósfera terrestre, hecho que habría de tener consecuencias inmediatas en la investigación de los fenómenos meteorológicos.

Los globos de aire caliente, excesivamente voluminosos y pesados, no podían ascender demasiado, ya que su peso específico sólo podía llegar a igualarse con el de un volumen análogo de aire situado a tan sólo unos mil metros de altura. En principio, cualquier anotación sobre las modificaciones de la temperatura y de la presión atmosférica que se pretendiera realizar, debería de efectuarse en esa estrecha franja; por otra parte, el aire encerrado en el globo se condensaba tan rápidamente - en ello tardaba pocos minutos, según fuese el tamańo del saco y la temperatura interna-, que los aeronautas se veían obligados a prestar casi toda su atención a reavivar el fuego de la estufa que portaban en el cestón. La preocupación fundamental de quienes viajaban en dichos globos era, pues, conseguir un grado ideal de calentamiento del aire para procurar el ascenso, el descenso o el estacionamiento de la nave en la atmósfera, empresa que les llevaba la mayor parte del tiempo sin que hubiera posibilidad material de registrar las variaciones detectadas por los aparatos. Cuando las materias combustibles que portaban se les acabasen, el globo descendería irremediablemente y las únicas conclusiones 
cientificas de su viaje aéreo se reducirían a la observación de los efectos del mismo en sus propios organismos o en los de los animales que les acompañaban, así como la forma en que las ráfagas de viento de las capas atmosféricas inferiores arrastraban caprichosamente de un lado a otro la nave; desde tierra, se podía calcular la altura aproximada alcanzada por el globo y el tiempo de vuelo, así como las velocidades de ascenso, desplazamiento y descenso ${ }^{6}$.

Los globos de hidrógeno, por el contrario, presentaban muchas más ventajas en cuanto a su utilidad en expediciones de carácter cientifico. La extraordinaria ligereza del gas, su dificultad para condensarse y la envoltura resinosa del saco, que impedía el escape del fluido, hacían posibles tanto los ascensos elevados, rápidos y duraderos como la realización de mediciones y las indagaciones sobre diversas cuestiones relativas a la atmósfera terrestre. De hecho, ninguno de los vuelos aerostáticos tripulados y con fines científicos que vamos a comentar aquí fueron realizados en globos de aire caliente.

Respecto a la meteorología, la mayor parte de las observaciones efectuadas durante los siglos XVII, XVIII e incluso parte del XIX, se hicieron a bajas alturas. Si exceptuamos las observaciones de J. A. Deluc y H. B. de Saussure y otros cientificos y montaneros ${ }^{7}$, las mediciones se solían realizar en lugares que no se distanciaban más que unos pocos metros del suelo, como campanarios de iglesias, torreones de castillos, lomas suaves y poco elevadas, etc.; sólo con la invención del globo aerostático de hidrógeno se abrieron las puertas a las investigaciones meteorológicas a grandes alturas ${ }^{8}$, por encima incluso de las más altas cotas conocidas, lo que por su parte favorecería a la larga el desarrollo de los instrumentos meteorológicos. Los que portaron Charles y Robert en su vuelo del 1 de diciembre de 1783, tenían más la función de controlar las variaciones de temperatura y presión que pudiesen afectar al vuelo mismo que la de efectuar investigaciones atmosféricas. Precisamente fue esto último lo que intuiría Priestley tan

${ }^{6}$ Véase FAUJAS DE SAINT FOND, Description des expériences de la machine aérostatique de $M M$. De Montgolfier, Paris, 1784, p. 34. Se necesitaban al menos tres observadores provistos cada uno de un cuarto de círculo y de un péndulo que batiera segundos.

7 Véase FeldMaN, Th. S., "Applied mathematics and the quantification of experimental physics: The example of barometric hypsometry", Historical Studies in the Physical Sciences, 15 (1985): 127-197.

' Y a lugares más o menos alejados de los puntos de despegue, según la fuerza con que el viento arrastrase las aeronaves. 
sólo dos semanas después; en una carta dirigida el 14 de diciembre de ese año a Sir J. Banks, presidente de la Royal Society de Londres, le decía que el futuro de los globos habría de ser el de convertirse en elementos imprescindibles para la exploración de las altas capas de la atmósfera'; en efecto, durante la ascensión realizada por el médico estadounidense J. Jeffries el 30 de noviembre de 1784 desde Londres, éste tomó varias muestras de aire a distintas alturas para ser posteriormente analizadas por $\mathrm{H}$. Cavendish, quien determinó que sus composiciones químicas no diferían para nada entre sí ni de la del aire tomado en las inmediaciones de la superficie terrestre ${ }^{10}$. Además, Jeffries se propuso determinar la presión y la temperatura a elevaciones diversas, así como observar las corrientes de aire para tratar de arrojar algo de luz sobre la teoría de la formación de los vientos; constató que la temperatura disminuía rápidamente a medida que se elevaba y que otro tanto ocurría con la presión atmosférica y con el grado de humedad del aire. Más tarde, el 7 de enero de 1785, acompañado por J. P. Blanchard, Jeffries cruzó en globo el Canal de la Mancha llevando a bordo un termómetro, un barómetro, un electrómetro, un higrómetro, un reloj y una aguja náutica ${ }^{11}$; los instrumentos - especialmente los dos primeros - fueron indispensables para navegar con éxito, pero no pudieron llegar a realizar mediciones meteorológicas de interés debido a los continuos percances sufridos durante el vuelo $^{12}$. Lo mismo que Charles y Robert, soltaron antes de partir varios globospiloto ${ }^{13}$ para observar la dirección y la fuerza del viento y hacerse una idea de lo que se encontrarían arriba; parece ser que también portaban una botella para

${ }^{9}$ Middleton, W. E. K., The Invention of Meteorological Instruments, Baltimore, The John Hopkins Press, 1969, p. 288.

${ }_{10}$ WOLF, A., A History of Science, Technology, and Philosophy in the $18^{\text {ch }}$ century, vol. 2, Londres, Thoemmes Press, 1999, p. 580.

${ }^{11}$ MidDLETON, W. E. K., op. cit., p. 288.

${ }^{12}$ Jeffries redactó un informe de sus dos experiencias aerostáticas: A narrative of the Two Aerial Voyages of Doctor Jeffries with Mons. Blanchard, Londres, 1786. De él se hace una referencia en GiLLISPIE, Ch. C., op. cit., pp. 44-56 ; también en Jackson, D. D., Les aéronautes, Amsterdam, Time-Life, 1981, p. 111.

${ }^{13}$ Este hecho fue recogido en la Gazeta de Madrid del sábado, 30 de diciembre de 1783 y muestra la colaboración que existía entre Montgolfier y Charles, que por la época ya eran miembros de la Academia de Ciencias de Paris: «El día 1. con la máquina aerostática de los Sres. Charles y Robert. Antes, Mr. Montgolfier, autor de este descubrimiento curioso, había echado á volar un globillo verde, que se perdió de vista en pocos minutos". El mismo Charles, en el discurso de apertura de uno de sus célebres cursos de física experimental, pronunció las siguientes palabras que fueron publicadas en el Mercurio Histórico $y$ Poltitico, diciembre (1783), vol. II, pp. 308-309: "A nuestro viage en el globo grande hicimos preceder el vuelo de un globo de 5 pies y 8 pulgadas de diámetro, el qual habiamos destinado 
tomar muestras de aire, pero el globo perdió tanto hidrógeno durante el trayecto que se vieron obligados a arrojar no sólo el lastre, sino también las provisiones, varios libros y la mencionada botella ${ }^{14}$. En general, el ejemplo de Charles y Robert fue seguido por los aeronautas que les sucedieron y, a pesar de que no todos ellos fueran conscientes de la importante sugerencia de Priestley y se propusieran más bien realizar vuelos de exhibición, tomaron la costumbre de llevar al menos termómetros y barómetros consigo.

Buena parte de las investigaciones realizadas por los aeronautas europeos de finales del siglo XVIII y comienzos del XIX, versaron sobre los proyectos para dirigir globos; pero, después de muchos fracasos, se centraron en las ascensiones de carácter científico. Así, A. V. Humboldt y J. P. Bonpland alcanzaron en 1802 los 5.878 metros de altura con el fin de observar la presión y la temperatura atmosférica; el 18 de julio de 1803, E. Robertson, más conocido como aeronauta que como hombre de ciencia, se elevó desde Hamburgo junto con su amigo, el profesor de música Lhoëst, pero la falta de sistematicidad en las observaciones efectuadas hacen dudar de la frabilidad de sus resultados ${ }^{15}$. Ese mismo año, por encargo de la Academia de Ciencias de San Petersburgo, ascendió a 7.000 metros junto al aeronauta Sajarov, con el objeto de estudiar el magnetismo terrestre y el estado eléctrico del aire en las sucesivas capas atmosféricas; creyeron observar un debilitamiento en la fuerza magnética que actuaba sobre la aguja imantada de la brújula conforme el globo ascendía y su conclusión fue que había una supuesta proporcionalidad inversa entre ambas ${ }^{16}$, coincidiendo así con la opinión de $\mathrm{H}$. B. de Saussure ${ }^{17}$. No conforme con dicho resultado, Laplace instó a la Academia de Ciencias de París a que se llevara a cabo una experiencia similar; los encargados de la investigación fueron J. B. Biot y J. L. Gay-Lussac, quienes refutaron la tesis anterior, como tendremos ocasión de comprobar más adelante.

para que nos manifestase la primera direccion del viento, y nos abriese, para decirlo así, el camino por donde debiamos transitar. Presentamos este globo pequeño á Mr. Montgolfier, y no fue difícil al público adivinar el sentido verdadero de esta sencilla alegoría; y no bien hubo cortado la cuerda este célebre Físico, quando el globo penetró rapidamente los ayres, seguido de las aclamaciones del inmenso número de pueblo que se hallaba presente".

${ }^{14}$ NaVARro MARQUEZ, E, Historia de la navegación atrea, Madrid, Alianza Editorial, 1970 , pp. 37-38.

${ }^{15}$ Véase JACKSON, D. D., op. cit., p. 112.

${ }^{16}$ NAVARRO MARQUEZ, E., op. cit., p. 44.

${ }^{17}$ Mediciones hechas en el pico Col du Géant (Alpes suizos). 
Después de los viajes de estos últimos, la aerostación científica experimentó un largo período de estancamiento, interrumpido ocasionalmente por algunos intentos no demasiado exitosos - como el protagonizado en 1808 por los meteorólogos italianos P. Andreoli y C. Brioschi, que ascendieron a 7.600 metros-o por alguna otra aventura aislada en Alemania e Inglaterra. Sólo en 1850, los aeronautas franceses Barral y Bixio ascendieron en un globo para estudiar la composición química del aire, pero no llegaron a cumplir sus propósitos al rasgarse la envoltura del aerostato; en un segundo viaje, en el que alcanzaron los 7.000 metros, descubrieron que los cirros se componían esencialmente de cristales de hielo $^{18}$. A partir de ese momento, la aerostación científica recobró interés en Europa y se sucedió una larga serie de nombres que se prolongó hasta el primer tercio del siglo XX.

\section{El aerostato de Dijon}

A comienzos del año 1784, tras el éxito de Charles y Robert, la Academia de Ciencias y Artes de Dijon encargó al químico L. B. Guyton de Morveau y a sus colaboradores Chaussier y Bertrand un estudio exhaustivo de los globos de aire caliente y de hidrógeno: procesos respectivos de construcción, materiales empleados, principios en los que se basaba su funcionamiento, autonomías de vuelo, proyectos para dirigirlos horizontalmente en el aire y posibles aplicaciones técnicas, sociales, científicas, militares, etc ${ }^{19}$. Aunque las experiencias realizadas los días 25 de abril, 30 de mayo y 12 de junio de 1784 tuvieron como finalidad principal comprobar el funcionamiento del globo de hidrógeno que diseñaron y poner a prueba sus elementos direccionales ${ }^{20}(\text { fig. } 1)^{21}$, las derivaciones desprendidas acerca de diversos aspectos del conocimiento de la atmósfera nos servirán para estudiar las aplicaciones científicas de los aerostatos.

${ }^{18}$ JACKSON, D. D., op. cit., p. 112.

${ }^{19}$ Véase GưTON DE MORVEAU et al. Description de l'Aérostat, Académie des Sciences, des Arts et des Lettres de Dijon, 1784. En la introducción, los autores dan cuenta del encargo y de los objetivos de su estudio, los cuales exponen y desarrollan a lo largo de toda la obra.

${ }^{20}$ Finalmente, la eficacia de éstos fue más que dudosa.

${ }^{21}$ En la ilustración aportada por Guyton de Morveau y sus colaboradores en op. cit., Pl. II, Fig. 1 y Fig. 3, p. 226, puede apreciarse un detalle del timón y de las alas, respectivamente. 


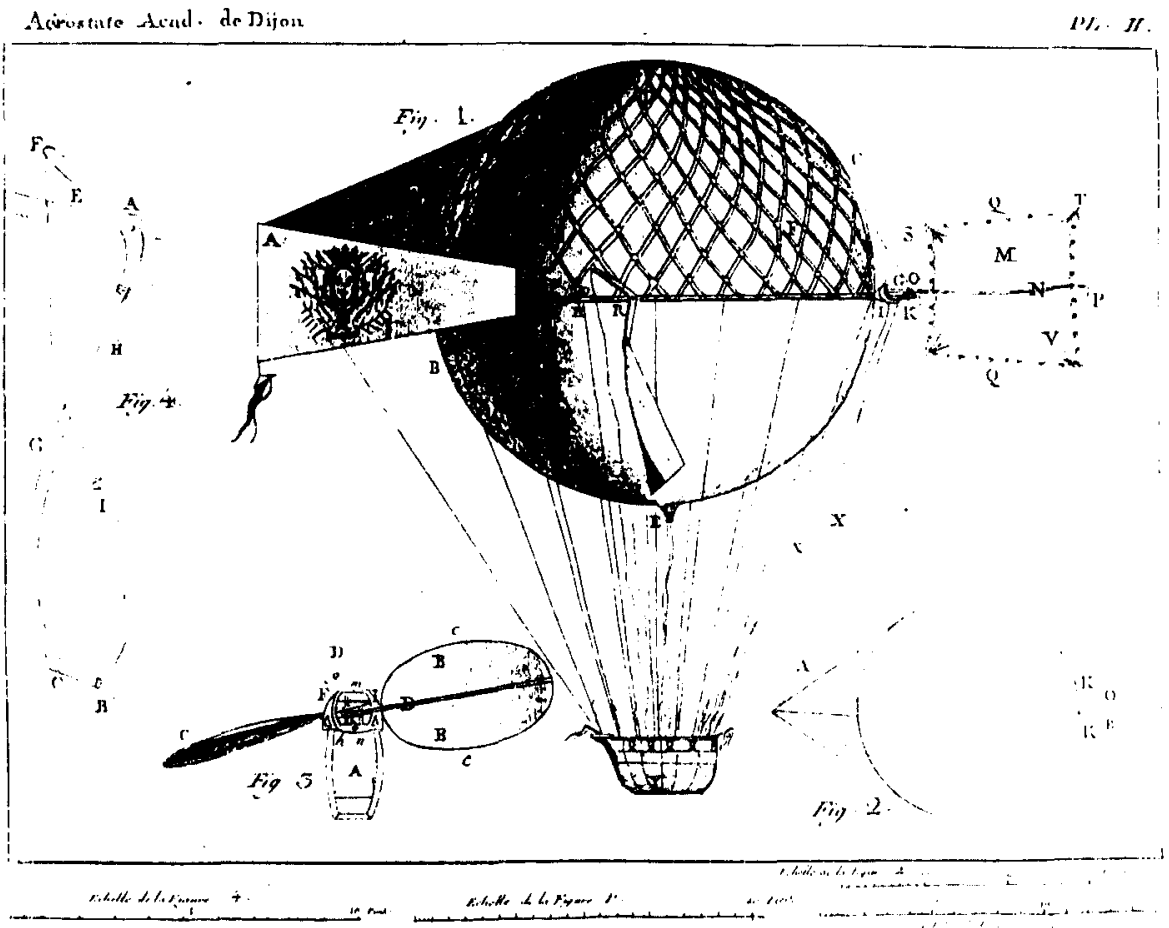

Figura 1. Aerostato de la Academia de Dijon. Fuente: Guyton de Morveau, Chauffier, Bertrand, Description de l'Atrostat, 1784.

En efecto, varias de las conclusiones a las que se llegaron atañían a determinadas cuestiones meteorológicas: localización de las corrientes aéreas en las capas inferiores de la atmósfera y variaciones térmicas, barométricas e higrométricas con la altura. De hecho, Guyton de Morveau se mostraba convencido de que la máquina aerostática llegaría a ser un elemento imprescindible para la observación de los vientos, contribuyendo así al consiguiente perfeccionamiento de esta rama de la meteorología. Lo mismo que ocurrió con los globos que partieron desde la Muette, las Tullerías o los Campos de Marte el año anterior ${ }^{22}$, su propia experiencia le demostró que «a cierta altura, la atmósfera dejaba de estar agitada

${ }^{22}$ Vuelos realizados en globos los hermanos Montgolfier y de Charles. Véase ValiES I RovirA, op. cit., pp. 29-40. 
con el mismo ímpetu y dirección que en la superficie de la tierra ${ }^{23}$. Cuando Guyton y el abate Bertrand se elevaron el 25 de abril, el viento de oeste-noroeste era tan fuerte que, a pesar del fuerte empuje ascendente, arrastraba el aerostato obligándole a describir una curva de 140 o 150 pies de radio; sin embargo, al alcanzar los 300 pies de altura, dejaron de experimentar turbulencias y la pequena llama que encendieron en la proa de la nave no sufrió ni la más mínima agitación, estado en que continuó cuando el globo alcanzó el punto más alto de su vuelo. Tomando como referencia la plomada y los puntos señalados por las cuerdas que pendían del círculo ecuatorial de la nave, confirmaron que el aerostato no vio alterada su trayectoria por ninguna corriente horizontal; sólo al descender y encontrarse cerca de la superficie terrestre volvió el globo a ser zarandeado por el viento. La conclusión fue que éste se originaba en las capas inferiores de la atmósfera, confirmando así lo que desde tierra se había observado frecuentemente: a menudo, las veletas indicaban que la dirección del viento no coincidía con la emprendida por las nubes.

En el momento del despegue, el barómetro marcaba 27 pulgadas y 6 líne$a^{24}$, mientras que el termómetro indicaba una temperatura de 11 grados sobre cero en la escala de Réaumur. Después de atravesar las primeras capas, hicieron nuevas mediciones: el barómetro había bajado a 20 pulgadas y 9 líneas, el termómetro a un grado y medio sobre cero y el higrómetro indicaba 59 grados en la escala de Retz ${ }^{25}$ y 24,5 en la de Copineau ${ }^{26}$. Las mediciones posteriores mostraban un descenso de la temperatura y de la presión con la altura, así como un grado creciente de sequedad en la atmósfera. El barómetro que llevaban fue construido por Goubert ${ }^{27}$ y era en todo análogo al barómetro portátil de J. A. Deluc ${ }^{28}$, con la excepción de que se había sustituido el

${ }^{23}$ Guyton de Morveau, et al., op. cit., p. 113.

${ }^{24} 1$ pulgada = 12 líneas; 1 línea = 2,257 milímetros.

${ }^{25}$ El higrómetro de Retz era una versión del higrómetro de Deluc. Ver MIDDLETON, W. E. K. op. cit., p. 99.

${ }^{26}$ GUYTON DE MORVEAU, op. cit., p. 181.

27 Este constructor de instrumentos científicos trabajó en la calle Dauphine de París y en 1781 publicó una obra titulada Description et usage des barometres, thermometres et autres instruments météorologiques, muy estimada por el meteorólogo L. Cottes (véase W. E. K. Middeton, $A$ History of the Thermometer and its use in Meteorology, Baltimore, The Johns Hopkins Press, 1966, pp. 134-135).

${ }^{28}$ Los dos termómetros de su barómetro servian para hacer sendas correcciones: una en función de la temperatura del mercurio y otra en función de la temperatura del aire. Véase 
grifo por un pistón deslizante en un tapón de corcho que se encontraba hundido en una tubuladura adaptada a la rama inferior; fue utilizado como altímetro ${ }^{29} \mathrm{y}$, siguiendo la regla de Cassini y Miraldi ${ }^{30}$, los aeronautas dedujeron que la altura alcanzada fue de 2.106 toesas $^{31}$ (según la regla de Deluc ${ }^{32}, 1.644$ toesas).

El vuelo del 30 de mayo se vio frustrado al romperse el círculo ecuatorial del globo y una de las alas, por lo que tuvieron que postergarlo para el 12 de junio. Por aquellos días, las nubes estaban fuertemente cargadas de electricidad y tuvieron que adjuntar a la máquina un conductor y un electrómetro ${ }^{33}$ para ponerse en guardia contra las explosiones del gas. El conductor consistía en un hilo de latón de una línea de diámetro y tres pies de largo, terminado en una punta fina; en el otro extremo había una trenza de falso galón enrollada de 110 pies $^{34}$ de largo; el hilo de latón apuntaba hacia delante y terminaba en dos bucles por los que pasaba un cordón de seda que tenía uno de sus cabos atado a la parte más avanzada del aerostato y volvía a pasar por

MIDDLETON, W. E. K., 1969, pp. 35-37 y TURNER, A., Early scientific instruments, Europe, 1400 1800, Londres, Sotheby's Pub, 1987, p. 261; también Feldman, Th. S., "Barometer», en Bud, R. \& WARNER, D. J. (eds.), op. cit.: 52-54.

${ }^{29}$ Sobre los orígenes de la hipsometría barométrica, véase FELDMAN, Th. S., op. cit., pp. 129138.

${ }^{30}$ Ibid., p. 133. También WOLF, A., op. cit., p. 289: "Miraldi llegó a la regla de que una ascensión de 61 pies desde el nivel del mar correspondía a una caída de una línea en la columna barométrica; una elevación de 62 pies correspondía a una caída de una segunda línea, y que las sucesivas elevaciones de $63,64, \ldots$ pies deberian de corresponder a los subsecuentes descensos de presión. (Mem. De l'Acad. Roy. des Sciences, 1703). Esta regla fue adoptada por Cassini".

311 toesa $=6$ pies $=1,950$ metros.

32 Deluc encontró la siguiente fórmula para determinar la diferencia de altura entre dos observatorios situados en los Alpes:

$H=\{(\log c-\log b)+[(\log c-\log b) \times a] / 1000\} / 1000$

Donde $a$ es el número de grados por exceso o por defecto de la temperatura estándar (de su propia escala de temperatura); $b$ es la altura del mercurio en el barómetro situado en el observatorio más elevado; $c$ es la altura del mercurio en la columna barométrica situada en el observatorio menos elevado (véase WOLF, A., op. cit., p. 300; también FELDMAN, Th. S., op. cit., pp. 152-156).

33 Una descripción completa del electrómetro puede verse en HACKMANN, W. D., "Electrometer", BUD, R. \& WARNER, D. J. (eds.), op. cit., 1998, pp. 208-211. Véase también TURner, L'E., Nineteenth-Century Scientific Instruments. University of California Press, 1983, p. 200.

${ }^{34} 1$ pie $=12$ pulgadas $=32,5$ centímetros. 
un bucle de vidrio puesto a la misma altura y a poca distancia, en la proa de la nave ${ }^{35}$ (fig. 1) ${ }^{36}$. En cuanto al electrómetro, consistía en un vaso de vidrio cónico guarnecido en su base con hojas de estaño y portando en lo alto una vara de latón terminada en punta, de la cual había suspendidas en el interior, mediante hilos metálicos, dos pequeñas bolas de saúco. Estaba atado al conductor por un cordón de seda de forma que sólo podía tocarlo por su base ${ }^{37}$ (fig. 1) ${ }^{38}$.

El 12 de junio subieron a bordo Guyton de Morveau y Virly, un físico de la Academia de Ciencias de Dijon que le había ayudado anteriormente a experimentar con el peso del aire y el de los diferentes gases que pudieran haber servido para llenar el globo. Se proveyeron de un barómetro de Deluc, un termómetro de Réaumur, un higrómetro de Retz y otro de Saussure ${ }^{39}$ (fig. 2) que indicaba $83,5^{\circ}$ en el momento del despegue; además, llevaron dos botellas llenas de agua para vaciarlas en las alturas y tomar muestras de aire. Volvieron a experimentar las mismas modificaciones que en el viaje anterior: descenso del termómetro y del barómetro con la altura y disminución de la humedad del aire. Con la ayuda de una plomada iban comprobando todos los lugares que sobrevolaban y, gracias a la brújula, pudieron orientarse durante el trayecto; el abate Bertrand les seguía desde su observatorio con un anteojo y más tarde pudieron reunir todos los datos para trazar un plano del recorrido $(\text { fig. } 3)^{40}$. Pese a sus esfuerzos por manejar los mecanismos direccionales, llegaron a la conclusión de que fueron arrastrados por las corrientes de viento de las capas atmosféricas inferiores y que permanecían estacionarios en las superiores. Calcularon que la máxima altura

${ }^{35}$ Gutton de Morveau, op. cit., p. 191.

${ }^{36}$ Ibid., PL. II, Fig. 1, A, y Fig. 2, A, p. 226.

37 Ibid., p. 192.

${ }^{38}$ Ibid., PL. II, Fig. 1, A, p. 226.

${ }^{39}$ El higrómetro de cabello de H. B. de Saussure data de 1775 y, como se sabe, se basaba en tres principios físicos: la dilatación de una sustancia, la saturación higrométrica de una cantidad de aire y la condensación de una cantidad de vapor de agua por enfriamiento. Saussure hizo dos versiones del mismo: uno de laboratorio y otro portátil, útil tanto en sus expediciones como en los futuros viajes aerostáticos. Ver SIGRIST, R., "Les Essais sur l'hygrométrie (1783) ou l'art de la mesure précise», H. B. De Saussure (1740-1799), un régard sur la terre, Paris, Bibliothéque d'histoire des sciences, 2001, pp. 113-117. Sobre higrómetros, consúltese MIDDLETON, W. E. K., 1969, pp. 81-132; también Th. S. FeldMaN, "Hygrometer», Bud, R \& Warner, D. J. (eds.), op. cit., pp. 313-315.

${ }_{40}$ Ibid., PL. III, p. 227. 
alcanzada fue de 812 toesas (según la regla de Deluc); alli, el higrómetro de Saussure indicaba $65,5^{\circ}$ y el de Retz $45^{\circ}$, en tanto que el termómetro de Réaumur estaba en $15^{\circ}$.
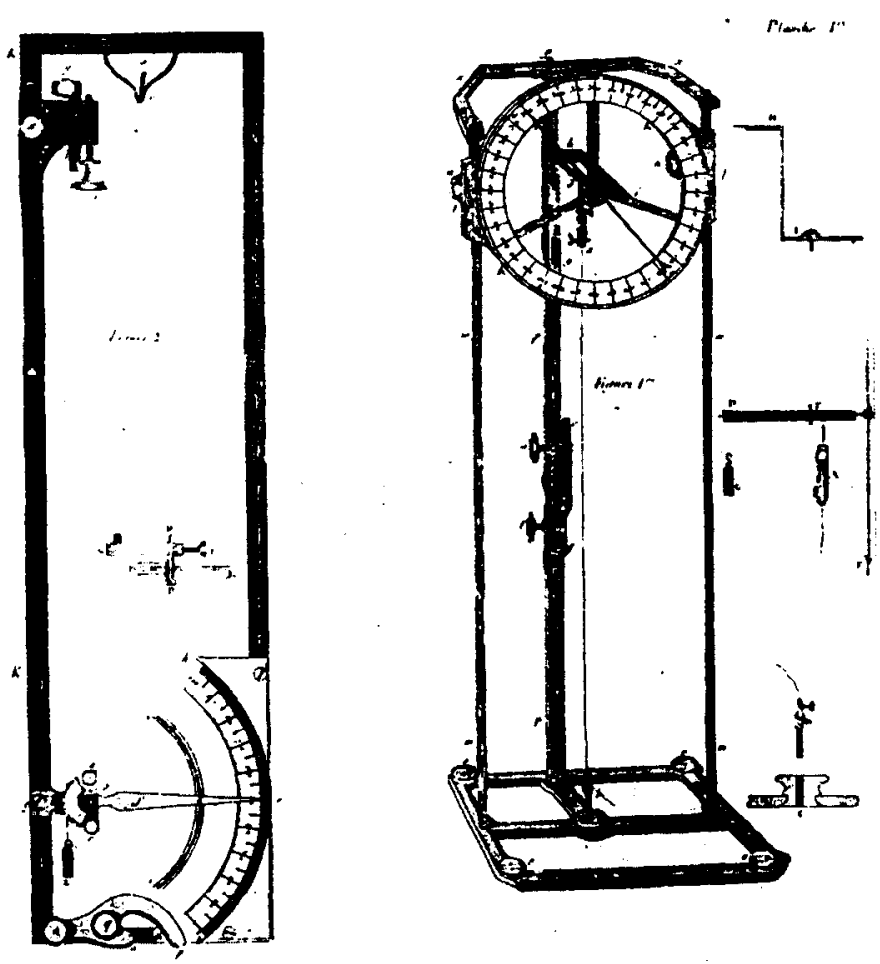

Figura 2. Higrómetros de H. B. de Saussure: portátil (izquierda) y fijo (derecha). Fuente: H. B. Saussure, Essais sur l'Hygrometrie, Neuchatel, 1783.

Durante el proceso de construcción del globo, habían notado que las envolturas de tafetán podían adquirir un calor considerable y que su dilatación crecía proporcionalmente; el 3 de junio observaron que el globo, llenado en sus tres cuartas partes de aire caliente y dejado la noche anterior a la intemperie, alcanzó a las 8 de la mañana una altura de cuatro pulgadas y media, lo que suponía un aumento de volumen de 84 pies cúbicos según sus propios cálculos. Por otra parte, el aumento de temperatura podía verse incrementado por la exposición directa del globo a los rayos solares y, a raíz de su experiencia del 25 de abril, atribuyeron a la dispersión de unas nubecillas la refrigeración del ambiente y la con- 
siguiente condensación del gas a una altura en la que el globo se encontraba estacionario ${ }^{41}$; por ello les pareció oportuno incorporar un instrumento para avisarles de las posibles contracciones o dilataciones del saco. Se valieron de uno construido en la propia Academia de Dijon ${ }^{42}$ y que consistía en un sifón de tres ramas; la primera era casi un capilar que comunicaba por un grifo con una vasija llena de aire; la segunda, muy gruesa, contenía un licor coloreado que subía y bajaba a medida que el aire de la vasija se rarificaba o condensaba y la tabla sobre la que se encontraba fijada llevaba divisiones en líneas y pulgadas cúbicas. Para que la indicación de las dilataciones fuera fiable, el instrumento debía de estar orientado hacia el sol, en la misma dirección en que lo estaba el globo; además, debería de contener la misma clase de gas que el globo y estar encerrado en un recipiente del mismo material que su envoltura ${ }^{43}$.

No llegaron a hacer mediciones con el electrómetro; en cuanto a las botellas de agua, tampoco tuvieron ocasión de vaciarlas por miedo a deslastrar demasiado. Con todo, obtuvieron datos relevantes sobre el estado de la atmósfera y sus modificaciones con la altura; sus esfuerzos encontrarían más tarde merecida recompensa, pues la práctica que siguieron serviría de ejemplo a científicos que, como Biot y Gay-Lussac, terminarían por perfeccionar sus métodos y completar el trabajo.

\section{«Relation d'un voyage aérostatique»}

Con este título publicaron J. B. Biot y J. L. Gay-Lussac una memoria en la que relataban las experiencias aerostáticas del 24 de agosto y 16 de septiembre de 1804 , cuando se propusieron realizar un estudio sobre ciertos problemas relativos a la atmósfera.

El fin principal del vuelo de agosto era examinar si la declinación magnética experimentaba alguna disminución al alejarse de la superficie terrestre. Saussure, a propósito de sus experiencias a 3435 metros de altura en los Alpes, creyó reconocerla y la evaluó en $1 / 5$. Algunos físicos y aeronautas pensaron que esta propiedad se perdía totalmente al alejarse de la tierra en un globo. Para comprobar si realmente ocurría así, tan sólo se necesitaba un reloj y una aguja iman-

\footnotetext{
${ }^{41}$ Ibid., pp. 205-206.

42 Iba alojado en la proa de la góndola o cesta de la nave. Ibid., PL II, Fig. 1, Y, p. 226.

${ }^{43}$ Ibid., p. 206.
} 


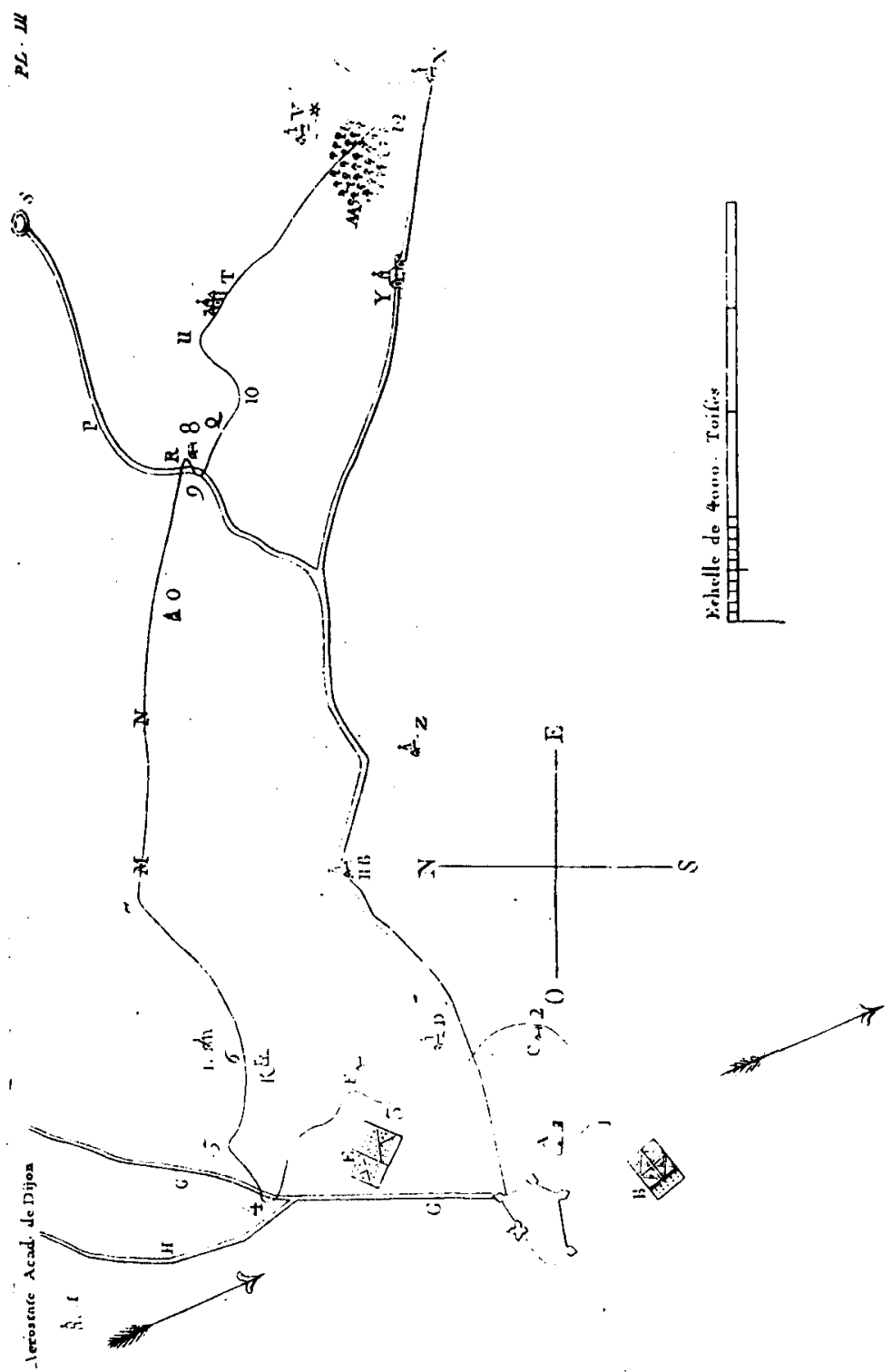

Figura 3. Trazado del recorrido efectuado por Guyton de Morveau el 12 de junio de 1784 en su globo. Fuente: Guyton de Morveau, et al., Description de l'Aerostat, 1784.

tada suspendidà en un hilo de seda muy fino: al desviarla de su meridiano magnético y dejarla oscilar libremente, la velocidad de las oscilaciones indicaría el 
grado de la fuerza magnética ${ }^{44}$; el reloj lo proporcionó el prestigioso constructor parisino J. A. Lépine ${ }^{45}$. Con el fin de no interferir en las mediciones, se evitó incorporar a la estructura del globo cualquier objeto metálico; los cuchillos y tijeras con los que embarcaron, fueron suspendidos de la nave a 10 metros por debajo de la cesta.

Otro de los objetivos del viaje era medir la electricidad del aire en las distintas capas atmosféricas, por lo que se proveyeron de hilos metálicos de diversas longitudes, desde 20 hasta 100 metros. También disponían de un electróforo cargado para determinar la naturaleza de dicha electricidad, habiendo sido frotada la resina en tierra antes de salir ${ }^{46}$. También se propusieron tomar muestras de aire, valiéndose de un globo de vidrio cerrado en el que previamente se había hecho el vacío; portaban además termómetros, barómetros, electrómetros e higrómetros. Llevaban discos de metal con los que pretendían repetir las experiencias de Volta sobre la electricidad desarrollada por simple contacto ${ }^{47}$ y viajaban con algunos animales, como ranas, pájaros e insectos para comprobar los efectos del vuelo en sus organismos.

${ }^{44}$ Los intentos por comparar las intensidades del campo magnético de la tierra en varias épocas y lugares empezaron a hacerse hacia finales del siglo dieciocho. El método empleado era comparar las frecuencias de oscilación de una aguja bajo diversas condiciones. Pioneros en este campo fueron el sueco F. Mallet (1769, Novi Commentarii Academiae Scientarum Petropolitanae), el francés Borda (1766) y el explorador A. V. Humboldt. El último dibujó un mapa que mostraba las zonas de la superficie de la tierra en las que la intensidad del campo magnético terrestre era aproximadamente el mismo; para ello se basó en las medidas hechas durante su viaje a América (1799-1803) y que publicó en un artículo titulado «Sur les variations du magnétisme terrestre à diferentes latitudes", en colaboración con Biot. Los datos fueron obtenidos al permitir a una aguja que oscilase en el meridiano magnético, observando después el número de oscilaciones ocurridas en diez minutos. Humboldt vio su descubrimiento de que la intensidad decrece desde el Polo hacia el Ecuador como el resultado más importante de su viaje a América. Ver WOLF, A. op. cit., p. 273.

45 (1720-1814). Ver Landes, D. S., Revolution in Time. Clocks and the Making of the Modern World, Cambridge - Massachussets - Londres, The Belknap Press of Harvard University Press, 1983 , pp. 265, 266, 450.

${ }^{46}$ El electróforo ideado por Volta data del úlrimo cuarto del siglo XVIII y se utilizaba, como es sabido, para electrizar por medio del fenómeno de la influencia eléctrica. Véase HeIlbron, J. L., Electricity in the 17th and 18th Centurias. A Study of Early Modern Physics, Berkeley, University of California Press, 1982, pp. 416-418.

${ }^{47}$ Para demostrar esta conocida propiedad, Volta necesitó tan sólo unas placas metálicas, un condensador y un electrómetro. Ver WOLF, A., op. cit., pp. 261-262. También HeILBRON, op. cit., p. 414. 
Salieron del Conservatoire des Arts et Métiers de París a las 10 de la mañana. A 2.000 metros de altura quisieron hacer oscilar la aguja, pero notaron que el aerostato experimentaba un lento movimiento de rotación que hacía variar la posición de la barquilla en relación a la de la aguja, lo que impedía observar el punto donde terminaban las oscilaciones. Mientras, observaron el desarrollo de la electricidad por el contacto de metales aislados y vieron que todo se producía de la misma manera que en la superficie terrestre. A 2.622 metros de altura, los animales no parecían sufrir ningún efecto pernicioso debido a la rarefacción del aire; el barómetro y el termómetro descendieron, pero no llegaron a sentir frío y la respiración se producía normalmente, si bien sus pulsos estaban algo acelerados. Tras realizar nuevos intentos con la aguja magnética, llegaron a la conclusión de que ela propiedad magnética no experimenta ninguna disminución apreciable desde la superficie de la tierra hasta los 4.000 metros de altura; su acción entre ambos límites se manifiesta constantemente por los mismos efectos y siguiendo las mismas leyes ${ }^{48}$

No pudieron observar exactamente la inclinación de la barra imantada, de modo que no les fue posible afirmar con certeza que no experimentara ninguna variación. Sin embargo, lo creyeron bastante probable, pues la fuerza horizontal no se veía alterada para nada. Por falta de tiempo y la indisposición de los aparatos, no pudieron hacer mediciones sobre la declinación, pero también creían que era poco probable que variase; se propusieron comprobar en un vuelo futuro la composición química del aire y si ésta sufría variaciones con la altura. En cuanto a la temperatura, el termómetro mostraba que decrecía con la altura, lo que coincidía con los resultados previamente conocidos; igual ocurría con la presión atmosférica. El higrómetro, por su parte, indicaba una progresiva pérdida de la humedad con la altura.

El 16 de septiembre, Gay-Lussac emprendió un nuevo vuelo —esta vez en solitario - desde el mismo punto de partida que el anterior y con el firme objetivo de realizar todas las mediciones que quedaron pendientes y algunas nuevas, para lo que se proveyó de un auténtico gabinete de física experimental. Desde el Observatorio de París, el astrónomo Bouvard ${ }^{49}$ hizo un seguimiento del vuelo. A 3.032 metros de altura, Gay-Lussac hizo oscilar la aguja horizontal y obtuvo 20

${ }^{48} \mathrm{~J}$. B. BiOT y J. L. GaY-LuSSAC, "Relation d'un voyage aérostatique», Observations sur la physique, 59, (1804): 317.

${ }^{49}$ A. Bouvard (1767-1843), astrónomo francés que llegó a ser director del Observatorio de París, descubridor de ocho cometas y autor de unas tablas astronómicas de Júpiter, Saturno y Urano. Ver The New Encyclopaedia Britannica, Londres, 1993, tomo 2, p. 434. 
oscilaciones en $83 \mathrm{~s}$, mientras que en similares circunstancias en tierra se requerían 83,33 s, lo que significaba una diferencia despreciable. A la altura de 3.863 metros, encontró que el ángulo de inclinación de la aguja era el mismo que en tierra. Después, quiso observar la aguja de declinación, "la sequedad, favorecida por la acción del Sol en un aire rarificado, era tal que la brújula se vio alterada hasta el punto de hacer que se curvase la aguja y que se plegase el círculo metálico sobre el que habían sido trazadas las divisiones" " tomó unas medidas de la presión atmosférica que eran la resultante de hallar la media aritmética entre la indicación de dos barómetros. Las alturas alcanzadas fueron calculadas por el astrónomo Gouilly, según la fórmula de Laplace ${ }^{51}$.

Del análisis de sus mediciones, las cuales anotó en una tabla (fig. 4), GayLussac dedujo que las temperaturas seguían una marcha irregular con las correspondientes alturas, lo que provenía, a su juicio, de que la columna de mercurio del termómetro no había registrado a tiempo las variaciones de temperatura atmosférica, cosa que se podría haber subsanado si el aerostato se hubiese elevado más lentamente. No obstante, la tendencia general de la temperatura era la de disminuir con la elevación; tomando el intervalo de altura comprendido entre la tierra y 3691 metros, comprobó que la temperatura había descendido desde $30,75^{\circ} \mathrm{C}$ hasta $8,5^{\circ} \mathrm{C}$, por lo que al dividir la diferencia de alturas entre la diferencia de temperaturas, obtuvo un descenso de $1^{\circ} \mathrm{C}$ por cada 191,7 metros; repitiendo la misma operación con el intervalo comprendido entre $5,25^{\circ} \mathrm{C}$ y $0,5^{\circ} \mathrm{C}$, así como $0,0^{\circ} \mathrm{C}$ y $-9,5^{\circ} \mathrm{C}$, obtuvo en uno y otro caso una elevación de 241,6 metros por cada grado de descenso de la temperatura, lo que parecía indicar que "hacia la superficie de la tierra el calor sigue una ley menos decreciente que en lo alto de la atmósfera, y que enseguida, a mayores alturas, sigue una progresión aritmética decreciente» ${ }^{52}$. El balance final fue que "el calor ha disminui-

${ }^{50}$ Gay-Lussac, J. L., Biot, J. B., op. cit., p. 455.

${ }^{51} \mathrm{H}=18336(1+0,0024845 \operatorname{Cos} F)\left[1+2\left(t+t^{\prime}\right) / 1000\right]\left\{[(1+r) / a] \log \left(h / h^{\prime}\right)+(r / a)\right.$ $0,868589\}$

siendo: $\Phi=$ latitud del lugar ; $h=$ altura de la columna barométrica en la estación inferior; $h^{\prime}=$ altura de la columna barométrica en la estación superior; a = distancia del centro de la tierra a la estación inferior; $\mathbf{a}+\mathrm{r}=$ distancia del centro de la tierra hasta cierta altura de referencia; $\boldsymbol{t}=$ temperatura en la estación inferior; $t^{\prime}=$ temperatura en la estación superior. Esta fórmula es una revisión de la de J. A. Deluc y se admite para variaciones de la gravedad con la altura y la latitud (véase P. S. DE LAPLACE, Traité de Mécanique Célest. $t .4 .^{\circ}$. De la mesure des hauteurs par le baromètre ". París, 1805 - Bruselas, Culture et Civilisation, 1967, pp. 289-293.

52 GaY-LuSSAC, J. L., Biot, J. B., op. cit., p. 456. 
do como las alturas han aumentado y a cada grado de descenso de la temperatura corresponderá una elevación de 173,3 metros " ${ }^{53}$

El higrómetro tuvo una marcha bastante singular. En la superficie terrestre estaba a $57,5^{\circ}$, mientras que a 3.030 metros marcaba $60^{\circ}$; a partir de ahí, descendió constantemente hasta que el globo llegó a 5.267 metros, donde el higrómetro indicaba $27,5^{\circ}$; después, hasta llegar a 6.884 metros, remontó gradualmente y se situó en $34,5^{\circ}$. Para interpretar dichos resultados era preciso tener en cuenta la temperatura, y entonces se podía ver que la humedad de la atmósfera segúa una progresión extremadamente decreciente con la altura.

En cuanto a las oscilaciones magnéticas, Gay-Lussac hizo la media de todas las observaciones realizadas en vuelo y concluyó que se requerían 42,16 s para 10 oscilaciones de la aguja, mientras que el tiempo obtenido en tierra era de 42,20s, cantidad que difería muy poco de la anterior; en las capas más altas del aire, el tiempo era ligeramente inferior a 42,16 s, diferencia que podía deberse a errores propios de este tipo de experiencias, lo que le llevó a la conclusión de que "el conjunto de los resultados que acabo de presentar confirma y extiende el hecho que ya habiamos observado M. Biot y yo, y que prueba que, lo mismo que la gravitación universal, la fuerza magnética no experimenta ninguna variación sensible en las más altas cotas donde pudimos llegar" ${ }^{54}$. Gay-Lussac dio por bueno este resultado a pesar de no haber podido hacer experiencias sobre la inclinación de la aguja imantada, pues la fuerza horizontal no había variado, de modo que tampoco habría de hacerlo la fuerza magnética ${ }^{55}$. Por otra parte, a la altura de 4.511 metros, acercó a la aguja imantada, en la dirección de la fuerza magnética, la extremidad de una llave; la aguja fue atraída por dicha extremidad y luego fue repelida por la otra. Similar experiencia, repetida a 6.107 metros, arrojó el mismo resultado: una prueba más de la invariabilidad del magnetismo terrestre con la altura.

A 6.561 metros, Gay-Lussac abrió uno de los globos de vidrio en los que había practicado el vacío y a 6.636 metros abrió el otro. Ya de regreso, decidió

53 Ibid., p. 457.

${ }^{54}$ Ibid., p. 457.

55 «La fuerza que hace oscilar la aguja horizontal es necesariamente dependiente de la intensidad y de la dirección de la fuerza magnética misma, que está representada por el coseno del ángulo de inclinación de ésta» (Ibid., pp. 457-458). 


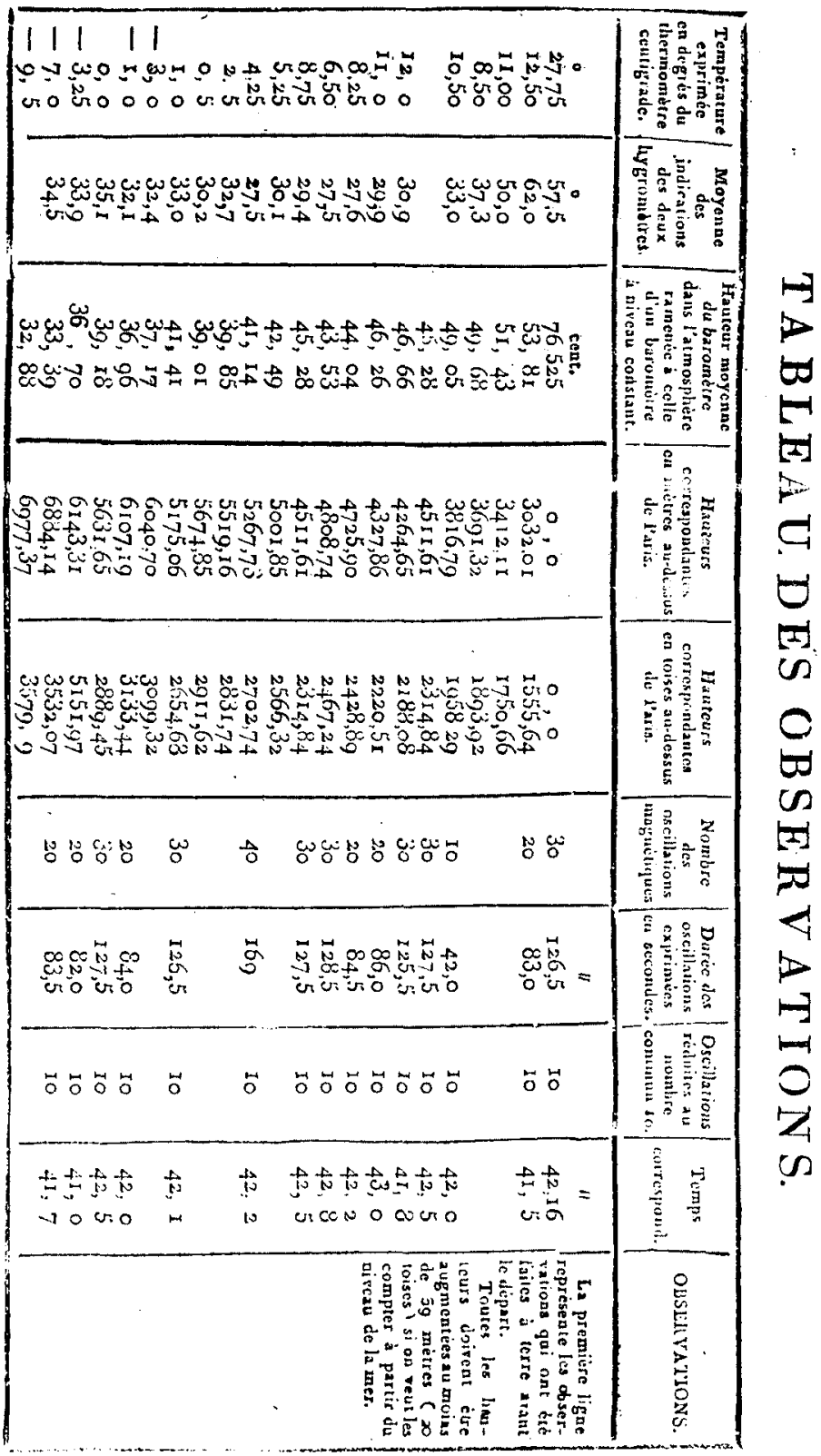

Figura 4. Tabla de las observaciones hechas por J. L. Gay-Lussac el 16 de septiembre de 1804 durante su viaje aerostático. Fuente: "Relation d'un voyage aérostatique»,

Observations sur la Physique, 59 (1804): 462. 
analizar las muestras en la Escuela Politécnica, asistido por los profesores de química Gresset y Thenard ${ }^{56}$, observando por turnos y separadamente las lecturas del eudiómetro de Volta ${ }^{57}$ y haciendo un análisis comparativo con el aire atmosférico tomado del patio de aquella institución. En todos los casos se obtuvieron resultados similares: $21,49 \%$ de oxígeno para el aire del primer globo y $21,63 \%$ del mismo gas para el segundo.

Idénticos resultados volvieron a obtener más tarde A. Von Humboldt y el propio Gay-Lussac ${ }^{58}$. En 1822, Boussingault, discípulo de Biot y de Gay-Lussac, realizó ascensiones aerostáticas en Colombia y se mostró conforme con ellos, habiendo seguido el mismo procedimiento que su maestro ${ }^{59}$. Por otra parte, J. Dalton, que no estaba de acuerdo con la composición cuantitativa del aire atmosférico encontrada por Gay-Lussac, realizó en 1833 ascensiones en globo a 2.888 y 4.500 metros de altura, obteniendo respectivamente un porcentaje de oxígeno de 20,52\% y 20,59\%; su conclusión fue que el aire atmosférico era más rico en oxígeno en las regiones habitadas y más rico en azote (nitrógeno) en las capas altas de la atmósfera ${ }^{60}$. De modo que aún en la primera mitad del siglo XIX había autores que estimaban que la composición del aire atmosférico era de un $20 \%$ de oxígeno y el resto de nitrógeno; otros, pensaban que el porcentaje era

56 De los dos citados, el más conocido es L. J. Thenard (1777-1857), autor de un influyente manual de química teórica y experimental y colaborador habitual de Gay-Lussac; fue también profesor de química de la Sorbona y diputado. Realizó trabajos sobre esteres y compuestos organofosfóricos y descubrió el peróxido de hidrógeno; fabricó un pigmento azul que en adelante serra muy utilizado en la coloración de la porcelana. Véase The New Encyclopaedia Britannica, op. cit., tomo 11, pp. 683-684.

${ }^{57}$ Sobre el eudiómetro de Volta, puede verse TURNER, G. L'E., op. cit.; p. 224. Más detalles se pueden encontrar en ROBERTS, L., «Eudiometer", BUD, R. \& WARNER, D. J. (eds.), op. cit., pp. 232 234 , donde también se habla de otras clases de eudiómetros y de los principios en que se basa su funcionamiento.

58 «Expériences sur les moyennes eudiomériques et sur la proportion des principes constituyants de l'atmosphére", Observations sur la physique, 60 (1804), pp. 129-168.

59 Para efectuar su análisis, contó con la colaboración de Dumas; fue publicado en «Recherches sur la véritable constitution de l'air atmosphérique", Annales de Chimie et de Physique, 3, III, nov. 1841, pp. 257-305.

${ }^{60}$ También H. B. De Saussure era de esta opinión; una vez tomadas las muestras de aire en el Col du Géant y en el Mont Blanc, las analizó siguiendo el método de Priestley, mezclando 1/3 de aire nitroso con 2/3 de aire común y midiendo la contracción con el eudiómetro de Volta. Llegó a la conclusión de que la proporción de oxígeno oscilaba en torno al $22 \%$, aunque disminuía con la altura. Véase: M. GrenON, "Les Observations météorologiques et climatiques de Saussure», en $H$. B. De Saussure (1740-1799), un régard sur la terre. París, Bibliothéque d'Histoire des Sciences, 2001, p. 151. 
$21 \%$ de oxígeno y $79 \%$ de nitrógeno; por fin, algunos sostenían que el aire variaba su composición cuantitativa con la altura ${ }^{61}$.

\section{Los inicios de la aerostación científica en España}

Los globos aerostáticos tuvieron, desde el primer momento de su recepción en España, una favorable acogida en los ámbitos científicos. Durante los primeros años, la aerostación se centró en el debate sobre la idoneidad de los globos de hidrógeno frente a los de aire caliente, en los proyectos para dirigirlos y en cuestiones aerométricas y gravimétricas; la mayor parte de los experimentos realizados en Castilla, Valencia y Cataluña estaban destinados a probar aquellos gases como propulsores de los globos, lo que no era óbice para que numerosos autores fuesen conscientes de la importancia de usar instrumentos científicos en las ascensiones y de la multitud de aplicaciones de dichos ingenios aéreos.

Así, P. A. De Salanova y Guilarte ${ }^{62}$ creía firmemente que desde los globos se podrían realizar observaciones astronómicas; la razón que aducía era que, al

${ }^{61}$ En diciembre de 1795, el catalán A. Martí i Franqués vio publicada en Continuación del Memorial Literario, Instructivo y Curioso de la Corte de Madrid su "Memoria sobre los varios métodos de medir la cantidad de ayre vital de la atmósferaw, en la que demostraba que la composición del aire atmosférico era bastante similar a la encontrada por Gay-Lussac, pero utilizó un eudiómetro de su propia invención y sulfuro saturado de mofeta (nitrógeno) como reactivo; en efecto, llegó a la conclusión de que el aire de la región donde vivía no estaba sometido a variaciones de ninguna clase en su composición, manteniéndose constantes las proporciones de $21 \%$ a $22 \%$ de oxígeno y $78 \%$ a $79 \%$ de nitrógeno, sin influir para nada ni la humedad ambiental, ni el estado eléctrico de la atmósfera, ni las variaciones de temperatura o presión (ver op. cit., p. 392). Puesto que, como él mismo afirmó, la composición del aire no variaba con las diferentes lecturas del barómetro, cabía esperar que tampoco lo hiciera con la altura. El eudiómetro de Marti, de su propia invención, consistía en "un tubo de cristal de 5 lineas de diámetro, y largo 10 pulgadas, está cerrado por uno de los extremos, y por este lado dividido en cien partes iguales, siendo de linea cada una de ellas, y que todas juntas comprenden á poca diferencia la capacidad de una onza de agua" (Ibid., p. 357). Su uso era sencillo: se llenaba el tubo de agua, en posición vertical y boca abajo, con el dedo pulgar en su abertura, para dejar que pasase poco a poco el aire exterior hasta ocupar 100 líneas, momento en que se sumergía el tubo en un recipiente con agua hasta adquirir su temperatura; luego se volvía a sacar y se comprobaba si el aire excedía o no las 100 líneas y se introducía éste en un frasco con reactivo que se tapaba y se sacudía durante cinco minutos para trasvasarlo luego al tubo graduado y leer los porcentajes.

62 Astrónomo, meteorólogo y redactor del Diario de Madrid; entre 1786 y 1795 realizó numerosas observaciones meteorológicas desde el Observatorio Astronómico de Madrid; véase LOPEZ PIÑERO, J. M. y otros, Diccionario histórico de la ciencia moderna en España, Barcelona, Península, 1983, vol. 2, pp. 282-283. Sobre las cuestiones referidas, véase SALANOVA y GUILARTE, Estática del ayre y náutica de la atmósfera, o disertación fisico-matemática sobre el origen, la invención, historia, fábrica, disposición, utilidades y perjuicios de las Máquinas o Globos Aërostáticos, Madrid, 1795, pp. 73-76. 
encontrarse el aire más limpio y libre de refracciones en las alturas ${ }^{63}$, se verían mejor los cuerpos celestes; también veía su utilidad en geografía y en topografía, pues se podrían determinar de forma bastante exacta, gracias a los telescopios, las posiciones y distancias recíprocas entre los lugares de la superficie terrestre. Incluso contemplaba la posibilidad de usar los globos para levantar cuerpos pesados o sacar barcos del fondo del agua ${ }^{64}$. En pneumática, los globos podrían ser muy útiles para reconocer la fluidez, el peso y la elasticidad del aire. Y, como cabía esperar, las aplicaciones de los globos a las investigaciones atmosféricas eran numerosas: estudio de las corrientes del aire, alteraciones y variaciones del termómetro y del barómetro con la altura, posibles modificaciones del magnetismo terrestre, declinación de la aguja náutica, efectos y modificaciones de la electricidad de la atmósfera ${ }^{65}$, propagación del sonido en el aire, refracción y refrangibilidad de los rayos solares al atravesar un prisma, etc.

${ }^{63}$ En la tercera parte de su obra, Salanova explica que cuanto más alejado estuviese el aire atmosférico de la superficie terrestre, más se parecería al éter newtoniano.

${ }^{64}$ En 1784, Guyton de Morveau presentó a la Academia de Ciencias de Dijon un método para extraer aguas de las minas inundadas valiéndose de un globo de hidrógeno y lo incluyó en un apéndice de su obra referida (pp. 219-224).

65 Salanova expone una curiosa teoría de la formación de los rayos que relaciona con las leyes de la hidrostática y con la acumulación de fluido eléctrico en la Tierra y en las nubes. La razón que aduce es que considera que ambos cuerpos son auténticas botellas de Leiden cargadas de electricidad, pero en diferente cantidad, de modo que ésta, como todo fluido, tiende a equilibrase pasando de uno a otro, momento en que se produce el rayo; éste fluye por el aire, conductor que comunica la Tierra con las nubes $\mathrm{y}$, puesto que por lo general la primera está más cargada que las segundas, el autor afirma que el rayo será casi siempre ascendente (véase Salanova y Guilarte, P. A., Disertación phtsico-electrica sobre las tempestades seguidas que acaecieron en Madrid los dias 20 y 21 de Junio del corriente año de 1792, y efectos de las fulminaciones que arrojáron á casa de Don Nicolás de los Heros, con su declaracion circunstanciada, Madrid, 1792, pp. 77-94). Obviamente, si los globos aerostáticos se elevaran provistos de electrómetros, se podría averiguar el estado eléctrico de las nubes, compararlo con el de la Tierra y prevenirse contra los rayos; fue precisamente esto último - y aun fueron más lejos- lo que ya apuntaron los redactores del Mercurio Histórico y Político del mes de octubre de 1783, sólo que atribuían las causas del rayo y de los fenómenos meteorológicos acuosos al traspaso de fluido eléctrico entre dos nubes desigualmente cargadas: «Una de las consequiencias que Mr. Quinquet saca de sus experimentos, es que podemos, por medio de los conductores eléctricos, preservar nuestros edificios de los rayos; pero las puntas que bastan para substraer la materia eléctrica de las nubes, no pueden extender su accion hasta las regiones mas elevadas en que se forman las tempestades. Quizá la máquina aerostática de Mr. Montgolfier, dispuesta de modo que sirviese de conductor, y siendo, como es, capaz de elevarse á alturas muy considerables, podria substraer á las nubes mas altas su materia eléctrica, y traspasarla á un estanque, á un pozo, á un rio ó á un arroyo, que servirian de receptáculo de la materia eléctrica, preservando de este modo las vińas, sembrados y frutales de 
De parecida opinión era J. Viera y Clavijo ${ }^{66}$, considerado durante mucho tiempo como el introductor de los globos aerostáticos en España ${ }^{67}$ y quien expuso, casi nueve años antes de que lo hiciera Salanova, ideas similares:

\section{XIX}

Lo eléctrico del ayre y variaciones,

La Física sabrá por esta vía

$Y$ sin nubes verá ni refracciones,

Cometa, eclipse, o faz la Astronomía;

Sus límites, sus grados, y extensiones,

Podrá fixar mejor la Geografía;

El comercio y Milicia harán progresos,

La maquinaria elevará más pesos. ${ }^{68}$

Incluso se atreve a hacer algunos pronósticos más arriesgados:

\section{XXI}

Bien podrá ser que un día la Fortuna

Haga nacer otro Colón segundo

Que emprenda navegar hasta la Luna,

Como aquel hizo viage al nuevo mundo;

Que un Herschel lince, sobre tal coluna,

Nuevos planetas halle en el profundo;

$\mathrm{Y}$ que algun Fontenelle tanto viva,

Que ande los astros y su Historia escriba. ${ }^{69}$

Por cierto, al volver Viera y Clavijo a España, tras su formación en París, colaboró con el marqués de Santa Cruz para montar un laboratorio de física y quí-

los efectos del granizo, cien veces mas dañosos que los del rayo. Si las experiencias de esta máquina en globos grandes prosiguen, como hasta ahora, justificando la invencion y perfeccionándola, se podrá responder con ésta, y otras muchas aplicaciones á los que desdeńosamente preguntan para que ha de servir la máquina de Mr. Montgolfier» (pp. 131-132).

${ }^{66}$ (1731-1813). Viera fue de J. A. Sigaud de la Fond en París, de quien aprendió química, así como de J. Ingenhousz en Viena. Véase LÓPEZ Piñero, J. M. y otros, op. cit., vol. 2, pp. 412-413.

${ }^{67}$ Hoy sabemos que el primer globo espanol fue construido por el también canario Agustín de Betancourt. Ver UTRILla NAVARRO, L., "El primer globo español», Betancourt, Los inicios de la ingenieria moderna en Europa, Madrid, CEHOPU-CEDEX, 1996, pp. 49-54.

${ }^{68}$ José VIERa y Clavijo, Los ayres fixos, Madrid, 1784, edición de 1876, Canto VI, p. 49.

${ }^{69}$ Ibid., pp. 49-50. 
mica en la casa de éste; gracias a la mediación de A. J. Cavanilles ${ }^{70}$, que aun permanecía en París, intentaron comprar parte del utillaje científico de Sigaud de la Fond, pero, ante la negativa del físico francés, tuvieron que encargarlos expresamente a varios constructores parisinos y al célebre técnico español D. Rostriaga ${ }^{71}$. Fue así como Viera pudo repetir los experimentos de su maestro y realizar varias pruebas con vejigas de animales llenas de hidrógeno ${ }^{72}$; además, adquirió una gran cantidad de conocimientos sobre experiencias aerostáticas, así como de física, química y botánica gracias a la correspondencia que mantenía con Cavanilles ${ }^{73}$.

Por lo demás, hasta la llegada de V. Lunardi a España, en 1792, los vuelos en globo no fueron tripulados. Hubo un intento frustrado, protagonizado por el francés Ch. Bouche, en Aranjuez ${ }^{74}$, tras su éxito en el lanzamiento de un globo de aire caliente en Valencia el 12 de marzo de $1784^{75}$ (dicho globo fue decorado por el propio aeronauta, pintor de profesión, que incluyó una imagen en la envoltura del globo en la que se podía ver "un león en actitud de custodiar diferentes instrumentos pertenecientes á la ciencia aerostática ${ }^{76}{ }^{7}$. Después de la experiencia de Bouche en Aranjuez, "ni las crónicas periodísticas ni los impresos anónimos recogieron ninguna otra información relativa a la actuación de algún aeronauta en el territorio del Estado español, hasta que llegó a Madrid Lunardi en $1792 \aleph^{77}$. Ni

${ }^{70}$ (1745-1804). En sus Cartas a José Viera y Clavijo, (edición a cargo de $A$. Cioranescu, Aula de Cultura de Tenerife, 1981), aportó numerosos datos sobre los globos aerostáticos y de los acontecimientos que en torno a ellos sucedieron en Francia.

71 (1713-1783). Rostriaga estudió en el Convento de Atocha de Madrid, donde se interesó por la construcción de relojes; más tarde, llegó a ser nombrado relojero de Fernando VI y, en 1764 , ingeniero de instrumentos de física y matemáticas y primer maquinista de física en el Real Seminario de Nobles. Ver GujJARro, V., Los instrumentos de la ciencia ilustrada, Madrid, UNED, 2002, pp. 121-125.

72 Véase Utrilla NaVARro, L., op. cit., pp. 50-51.

${ }^{73}$ Así, en su carta del 4 de mayo de 1784, le comenta el vuelo de Guyton de Morveau del 25 de abril del mismo año en Dijon. Véase Cavanilles, A., op. cit., p. 64.

${ }^{74} 6$ de junio de 1784. Globo de aire caliente que fue encargado construir a Bouche por orden del infante D. Gabriel. La nave se incendió y el aeronauta se vio obligado a lanzarse desde la galería a tierra, sin sufrir daño. Ver VAlués I Rovira, I., La màgia del vol, Barcelona, Alta Fulla, 1985 , pp. 68-73.

${ }_{75}$ El relato de este acontecimiento fue publicado en la Gazeta de Madrid del viernes, 23 de abril de 1784. En el artículo se menciona que previamente se soltó un globo de 28 pulgadas de diámetro, lleno de gas inflamable, para observar la dirección y la fuerza del viento, cuyo vuelo duró 35 minutos. Como ya venía siendo costumbre, en el globo de aire caliente embarcaron algunos animales domésticos para comprobar los efectos en sus organismos.

${ }^{76} \mathrm{Ibid}$.

77 Vallès i Rovira, I., op. cit., p. 84. 
siquiera F. Salvà i Campillo ${ }^{78}$, que intervino activamente junto con F. Sanponts i Roca $^{79}$ en la construcción de sendos globos que se elevaron desde Barcelona el 30 y el 31 de enero de 1784 por encargo de la Academia de Ciencias Naturales y Artes de aquella ciudad ${ }^{80}$, consiguió realizar un vuelo aerostático (fig. 5). Sin embargo, ambas experiencias sirvieron para confirmar una vez más algunas cuestiones relativas a la meteorologia y a la hipsometría:

Por las relaciones de los nuevos Argonautas consta, que à ciertas alturas se hallan diferentes corrientes de ayre con direcciones diversas, asi como en el mar se hallan los vientos Alisios con direcciones constantes. Los calculos de Mr. De Luc sobre las varias alturas halladas por el barómetro, y las que se podrian hacer con el termómetro, servirian como de bruxula para encontrar las corrientes, y la direccion que se desee. ${ }^{81}$

78 (1751-1828). Médico y físico; construyó diversos instrumentos científicos, como barómetros, termómetros e higrómetros. Véase Guijarro, $\mathrm{V}$., «El barómetro y los proyectos meteorológicos de la Ilustración", en este mismo número. También IGLÉSIES FORT, J., "La Real Academia de Ciencias Naturales y Artes en el siglo XVIII", Memorias de la Real Academia de Ciencias y Artes de Barcelona, tercera época, núm. 707, vol. XXXVI, núm. 1 (1964): 205-213.

${ }^{79}$ (1756-1821). Médico, físico e ingeniero que colaboró con F. Salvà i Campillo en numerosas investigaciones científicas. Ibid., pp. 219-222.

80 "El 3 de este mes de Enero se abrió una subscripcion nacional (por los Doctores Salvá y Sanpons) para hacer una por medio de la rarefacción del ayre con el fuego, ò como vulgarmente se llama, llena de humo de paja... El viento fuerte que reynó algunos dias, impidió hacer la experiencia hasta el 30 à las ocho de la mafiana" (GAMBORINO, M., Experiencias aerostáticas en Barcelona, Barcelona, 1784. El informe carece de numeración de páginas). El mismo dia 30, a instancias de la Academia de Ciencias y Artes de Barcelona, se propuso llenar otro globo con hidrógeno, extraido de diversas sustancias y por diversos procedimientos, en el jardín del palacio del conde de Aranda; se soltó el día siguiente y, aunque el autor proporciona datos sobre las lecturas barométricas y termométricas en tierra, sólo da una idea de la altura alcanzada en los diez primeros minutos gracias a la cuerda de 360 varas castellanas a la que estaba atado el globo (Ibid.).

${ }^{81}$ Gamborino, M., op. cit. 


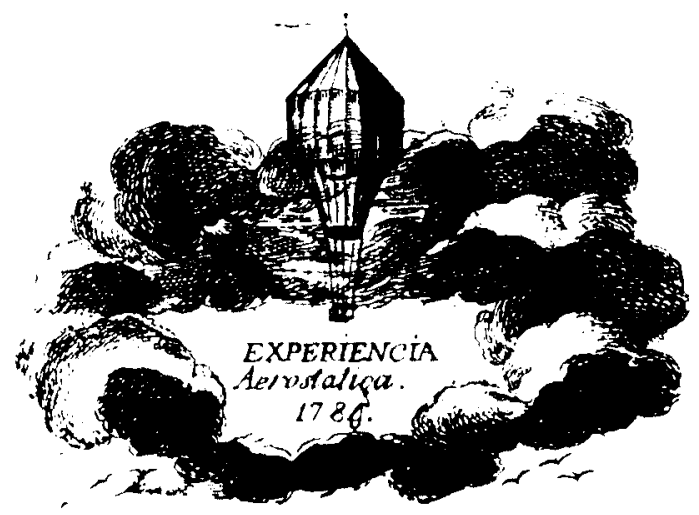

Figura 5. Ilustración de M. Gamborino que reproduce el primer globo lanzado en Barcelona. Estaba hecho de papel y su forma era una pirámide de base heptagonal. Tenía 20 pies de diámetro, 30 de altura y albergaba 8049 pies cúbicos de aire caliente; a bordo se encerró una gallina en una jaula (que volvió sana). El vuelo duró ocho minutos y la altura alcanzada por el aerostato fue de $\mathbf{4 5 0}$ toesas.

Fuente: M. Gamborino, Experiencias aerostáticas en Barcelona, 1784.

En general, la importancia de llevar instrumentos científicos a bordo no pasó desapercibida, al menos por lo que respecta a su utilidad como altímetro y para controlar las dilataciones del gas:

XIV

El Barometro fixa con acierto

Cárlos al barco que huye en alto bordo, Y Roberto hábil, y también experto, Inventariaba riquezas á bordo; Suben adonde el Sol esta despierto, $\mathrm{Y}$ adonde frio suena el ayre sordo, Que al arribar de Mousseaux á la izquierda, Ya el carro caminaba sin la cuerda ${ }^{82}$.

Como tampoco el hecho de que el frío se dejara notar más en las alturas, llegando a producir grandes molestias a los aeronautas:

${ }^{82}$ QueIPO de Llano y VALDÉs, J. J., Canto que en elogio de la brillante invencion del Globo Aërostatico y famosos viages aëreos escribia Cypariso, labrador asturiano, Madrid, 1784, p. 7. Este poema narra, principalmente, la hazaña de Charles y Robert del 1 de diciembre de 1783. 


\begin{abstract}
XLVII
Ni el dolor se disipa, ni destierra, Aunque usa de reparos convenientes, Hasta tanto que el centro de la tierra, Se retira con pasos diligentes;

La sensación, que el ayre frio aterra,

Disipan los vapores ya calientes,

$Y$ trata de dexar aquesta empresa, Y de cumplir al Duque la promesa ${ }^{83}$.
\end{abstract}

El contenido de ambas estrofas coincide con las propias declaraciones de Charles, quien más que efectuar observaciones meteorológicas propiamente dichas, utilizó el termómetro y el barómetro como instrumentos de navegación. ${ }^{84}$

\footnotetext{
${ }^{83}$ Se refiere al duque de Chartres, que fue testigo del vuelo de Charles y le felicitó por ello y por las utilidades prácticas del globo de hidrógeno (Ibid., p. 24).

${ }^{84}$ "Yo, sin embargo, no perdia de vista el barómetro; y Mr. Robert inventariaba las riquezas que teniamos a bordo... Entonces estaba el barómetro casi á 26 pulgadas, y habiamos cesado de subir, esto es, nos hallabamos elevados cerca de 300 toesas, que era la altura á que habiamos determinado mantenernos. En efecto, desde aquel instante hasta el en que desaparecimos á los ojos de los observadores, caminamos horizontalmente éntre 26 pulgadas, y 26 pulgadas y 8 líneas, lo qual se halló comprobado con las observaciones hechas en París... El termómetro se mantuvo mas de una hora éntre 10 y 12 grados debaxo de cero, lo qual procedió de que el interior de nuestro carro se habia calentado con los rayos del Sol. El mismo calor se comunicó á nuestro globo, el qual mediante la dilatación del ayre inflamable interior, continuó manteniéndose á la misma altura, sin necesidad de arrojar lastre... Desde mi partida empezé á tomar las precauciones necesarias para libertarme del peligro de la explosion del globo, y me dispuse á hacer las observaciones que tenia meditadas; y desde luego, con el fin de observar el barómetro y el termómetro, colocados en la extremidad del carro... El globo, que á mi partida tenia muy poca tension, se hinchó insensiblemente, y á poco empezó á salir el ayre por el apéndice con mucha fuerza. Entonces abrí de quando en quando la válvula para facilitarle á un mismo tiempo su salida, y de este modo continué en subir perdiendo ayre, el qual salia silvando y en forma de humo, ó como un vapor caliente que pasa por una atmósfera muy fria. La razon de este fenómeno es clara y sencilla. En tierra estaba el termómetro á 7 grados encima de la congelación; al cabo de 10 minutos de ascensión, se hallaba á 5 grados debaxo de la congelación; y ya se dexa conocer que el ayre inflamable contenido no habia tenido tiempo de ponerse en equilibrio de temperamento, y que, siendo su equilibrio elástico mucho mas pronto que el del calor, debia salir una porcion de ayre mucho mayor que la que podia producir la dilatación exterior del ayre por su menor presion... Quando el barómetro cesó de subir noté puntualisimamente 18 pulgadas y 10 líneas; y de su oscilación, que no era perceptible, inferí hallarme en un altura de cerca de 1524 toesas... En medio del extásis en que me hallaba, el qual no puede explicarse con palabras, me asaltó un dolor extraordinario en la oreja derecha, efecto sin duda así de la dilatación del ayre contenido en la textura celularia del organismo; como de la frialdad del ayre en aquella region.» CHARLES, J. A. C., en el discurso preliminar a uno de sus cursos de física experimental que fue publicado en Mercurio Histórico y Politico, diciembre (1783), vol. II: 308-323.
} 
De los tres viajes en globo protagonizados por Lunardi en Madrid, el del 8 de enero de 1793 será el que más nos interese. Desde su llegada a España, el célebre aeronauta italiano fue presentado en la corte por el duque de la Roca, quien convenció al rey para que se realizaran experiencias aerostáticas con fines científicos, especialmente los destinados al análisis del aire atmosférico y las variaciones de la temperatura, presión y humedad de la atmósfera con la altura. Lunardi colocó en la barquilla "un termometro y un barometro arreglados, como una bruxula y botellas llenas de agua, todo con animo de hacer en los ayres observaciones relativas á los diversos temperamentos de las partes de la atmosfera; á la elevación ó descenso del barometro, que indica la altura á que habrá subido, y á los rumbos que le habrán designado las corrientes del ayre, trayendo por especial comision de $S$. E. una botella de ayre superior ${ }^{85}$. No deja de ser importante el hecho de que Lunardi recabara datos sobre las modificaciones de las condiciones atmosféricas con la altura ${ }^{86}$ y de que, una vez más, llegara a las mismas conclusiones que los que le precedieron. Como ya era habitual, llevaba a bordo animales domésticos, los cuales no sufrieron ningún daño durante su viaje ${ }^{87}$. También pudo comprobar Lunardi lo mismo que Guyton de Morveau hizo nueve años antes al observar el comportamiento del viento: «que las corrientes del ayre en las diversas capas de la atmosfera no llevan una dirección constante y uniforme» ${ }^{8}$.

La botella con la muestra de aire tomada a la mayor elevación de su trayecto $^{89}$, fue entregada a dos farmacéuticos de los Reales Hospitales para su análisis: F. Hicedo y J. Gómez, quienes actuaban bajo las órdenes de J. Meneses,

${ }^{85}$ Diario de Madrid, 10 de enero de 1793.

${ }^{86}$ «El termómetro de Fahrenheit señalaba los 52 grados, y el de Réaumur los 10: esto es el tiempo templado. El barómetro estaba á los 24 grados y el higrómetro fixo en el ayre en calma, y manifestando un tiempo sereno; la aguja señalaba el Nornoroeste" ( IInforme escrito en italiano por el Capitan Don Vicente Lunardi y traducido al Castellano, en que refiere todo lo ocurrido en su ultimo viage aereo", Diario de Madrid, 15 de enero de 1793).

${ }^{87}$ Tampoco Lunardi padeció ningún mal: "Tengo la honra de poner noticia á V. E. Que hoy Martes á las cinco y quarto de la tarde he baxado por tercera vez, sin experimentar novedad alguna en mi salud" (Diario de Madrid, 11 de enero de 1793).

${ }^{88}$ Ibid.

${ }^{89}$ "Mi relox señalaba las dos y media de la tarde, quando en la elevación á que ascendí señalaba el barómetro los veinte y tres grados, y el termómetro cinco grados sobre el yelo. En esta altura, que fue la mayor que logré, fue menester que bebiera agua y licores para poder llenar principalmente una botella de ayre superior, ya que no habia podido obtenerlo antes, con animo de desempenar el particular encargo que me hizo el Excmo. Sr. Duque de la Roca, para que después se analizase este ayre, y se averiguaren las propiedades y modificaciones que contiene, según lo habia deseado $S$. E. Después de haberla llenado del todo la tapé perfectamente con un corcho, y corté un pedazo del cuello del 
alumno del director del Real Laboratorio de Química de Madrid y miembro de la Real Academia de Ciencias Naturales y Artes de Barcelona ${ }^{90}$ P. Gutiérrez Bueno ${ }^{91}$. La operación se efectuó con sumo cuidado, introduciendo la botella en un "aparato neumato-químico»" ${ }^{92}$ para evitar cualquier mezcla con el aire del laboratorio; resultó que la densidad de la muestra recogida por Lunardi era un $66 \%$ inferior a la del aire del lugar en que se encontraban. En dicho aparato hicieron las comparaciones relativas del aire de la botella con el aire del laboratorio, valiéndose del eudiómetro de Fontana ${ }^{93}$ ( fig. 6); tras observar los grados de absorción de ambas muestras de aire por el gas nitroso, "se vio que cada cien partes de este ayre, contenía veinte y siete del gas oxigeno, y setenta y tres del gas azootico. Repetimos los mismos ensayos con el ayre de la calle de Alcalá, y la uniformidad de los resultados, asegurandonos de la operación, nos hizo conocer que las partes constituyentes del ayre analizado, eran casi iguales á las de este último. En esta inteligencia podemos asegurar con datos innegables, que el ayre que corre en las alturas regulares sólo se diferencia del que nos rodea por estar más enrarecido, ó bien por el menor peso que gravita sobre él, ó por la variación de su temperatura ${ }^{94}$. Resultado que, salvo en lo concer-

Globo, con el qual le envolví la boca y le até con firmeza, todo á efecto de que no pudiera salir nada del ayre que contenía, ó que se mezclase con el que reinaba en las partes más baxas de la atmósfera" ("Informe escrito en italiano por el Capitán Don Vicente Lunardi y traducido al Castellano, en que refiere todo lo ocurrido en su ultimo viage aereon, Diario de Madrid, 16 de enero de 1793).

${ }^{90}$ Véase IGLESIES FORT, J., op..cit., pp. 226-227.

${ }^{91}$ Por aquellas fechas, Gutierrez Bueno era director del Real Laboratorio de Química de Madrid y disfrutaba de gran autoridad y prestigio en el mundo científico madrileño. Fue él quien proporcionó todo el utillaje y quien diseńó las directrices del experimento: «D. Pedro Gutiérrez Bueno, Catedrático por S. M. De dicho Real Laboratorio, nos franqueó todos los instrumentos y máquinas correspondientes a la operación que debíamos hacer, para examinar la naturaleza, y qualidades del ayre contenido dentro de una botella, en la qual había sido encerrado por D. Vicente Lunardi, quando se hallaba á la mayor elevación de su ultimo viage aerostático, hecho el día 8 de Enero de 1793 á presencia de SS.MM., y Real Familia” (Diario de Madrid, viernes, 18 de enero de 1793).

92 Ibid.

${ }^{93}$ Dicho instrumento se basa en la absorción del oxígeno por el gas nitroso (véase JoRDI, R., "Situación científica del boticario Juan Ameller ante el estudio experimental de la salubridad del aire atmosférico por medio del Eudiómetro". Circular Farmacéutica, 288, jul.- sept. (1985): 214248. Edición facsímil de la Memoria sobre el verdadero modo de determinar los grados de salubridad de diferentes atmósferas por medio del eudiometro del abate Fontana, y definición de este instrumento según dicho autor, Real Academia de Ciencias Naturales y Artes de Barcelona, 1792. Martí i Franqués (op. cit., pp. 266-267) objetó que la prueba de Fontana presentaba muchos inconvenientes, consecuencia de la imperfección misma de su aparato.

${ }^{94}$ Diario de Madrid, 18 de enero de 1793. 
niente a la composición cuantitativa del aire atmosférico ${ }^{95}$, coincidía con otros que ya hemos examinado.

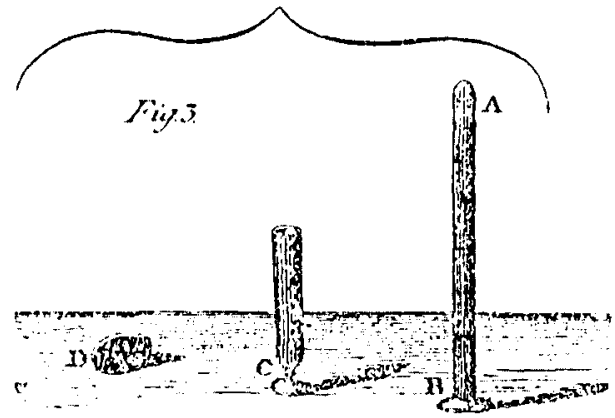

Figura 6. Eudiómetro de Fontana. Fuente: Sigaud de la Fond, J. A., Elementos de Física Teórica y Experimental, 1787, tomo 3, Lám. II, p. 76. Traducción española de Tadeo López Aguilar.

Lunardi decidió continuar su gira triunfal por Europa y realizó un memorable vuelo en Lisboa, el 24 de agosto de 1794. Hasta 1802, año en que regresó a España, las ascensiones en globos tripulados fueron más bien escasas: Joseph Campello se elevó el 10 de septiembre de 1797 en un globo cautivo a veinte metros de altura en Valencia; más prolífico fue Antoni Gull Macià, que en octubre de 1798 protagonizó otra ascensión en globo cautivo desde el huerto de Duclós (Valencia) y continuó sus experiencias hasta 1815, año en que murió cuando su globo libre chocó con la cima del campanario de la catedral. No se tienen noticias acerca del posible carácter cientifico de sus vuelos; probablemente fueron de exhibición, lo mismo que los efectuados por el francés Rogell en Valencia y Barcelona, de los que ni tan siquiera se dispone de documentación sobre el tipo de combustible utilizado. Por último, el 5 de noviembre de 1802, Lunardi se elevó en un globo de hidrógeno en Barcelona ante los reyes,

${ }^{5}$ A. QUINTANA I MARI (Aportació dels primers aeronautas al coneixement de la química de l'aire a les darreries del segle XVIII, Barcelona, Societat Catalana d'Historia de la Ciència i de la Tècnica, 1996, pp. 22-25) argumenta que la admiración inquebrantable de Gutiérrez Bueno por los químicos franceses, que seguían el método de Fontana para determinar la salubridad del aire atmosférico, contrasta con el rigor experimental de Martí i Franqués, más acertado en sus análisis. Probablemente el prestigio y la autoridad de Gutiérrez Bueno influyeron de forma negativa en el experimento de Hicedo y Gómez, que aceptaron sin más el dogmatismo impuesto por éste. 
que se habían trasladado allí para celebrar la boda de su hijo Fernando con la princesa de Nápoles, y la del hermano de ésta con Isabel, infanta de España; parece ser que el fuerte viento reinante arrastró el globo hacia el mar y tuvieron que sacarlo de allí unos marineros.

Poco más se puede añadir sobre los vuelos tripulados; la invasión napoleónica sumió a España en un período de declive económico y científico y los pocos vuelos que llegaron a efectuarse tenían un trasfondo festivo. Las potencias europeas $^{96}$, por el contrario, más fuertes económica y militarmente que España, buscaron la aplicación de la aerostación a la guerra, debiéndose a ésta principalmente su progreso ${ }^{97}$. Habría que esperar a la creación del Batallón de Telégrafos de Madrid por Alfonso XII ${ }^{98}$ para asistir a un nuevo resurgimiento de la aerostación española, contando entre sus actividades la realización de observaciones meteorológicas y astronómicas ${ }^{99}$.

\section{Conclusiones}

En los comienzos de la aerostación, sólo los globos de hidrógeno se mostraron aptos para realizar tareas de carácter científico, mientras que los de aire caliente tuvieron la tarea principal de ser lanzados antes que éstos para que los aeronautas pudieran hacerse una primera idea de la dirección y velocidad de las corrientes de aire; la ligereza de aquel gas posibilitaba la ascensión de los aerostatos a capas elevadas de la atmósfera, en tanto que su tardanza en condensarse facilitaba la prolongación del vuelo. Por otra parte, los elementos que incorporó J.

96 En Francia, G. Monge propuso el uso militar de los globos y el Gobierno aprobó una comisión en la que se hallaban Bertholet, Fourcroy, Guyton de Morveau, Perrier, Faypouth, Marre, Lavoisier, Curelle y el propio Monge; en 1794, el Comité de Salud Pública instituyó una compañía de aerosteros militares con sede en Meudon, bajo la dirección del físico y químico Conté, y ese mismo año Napoleón Bonaparte utilizó un globo cautivo de hidrógeno en la batalla de Fleurus, contra el ejército austriaco (véase TISSANDIER, G., Histoire des ballons et des aéronautes célebres, 1783-1800, París, 1887, pp. 134-142. En España, la iniciativa del conde de Aranda (Ensayo de un Globo Aërostatico, Real Academia de Artillería de Segovia, 1792), permitió que se realizara una experiencia aerostática con fines militares en la que participó el químico francés L. Proust, .

${ }_{97}$ Véase Gomá Orduña, J., Historia de la Aeronáutica Española, Madrid, Prensa Española, 1946; p. 43.

${ }_{98}$ Real Decreto de 15 de diciembre de 1884 . Ver LÁzaro Ávila, C. y Pérez Heras, A., La aerostación militar en España, Madrid, Ministerio de Defensa, 1995, p. 14.

99 Ibid., pp. 28-30. 
A. C. Charles a su estructura, permitían controlar las dilataciones del gas voluntariamente, proporcionando mayor seguridad a los tripulantes y haciendo posible que éstos desviaran sin peligro su atención hacia la medición de los parámetros atmosféricos que experimentaban modificaciones con la altura. No es casualidad que el propio Charles llevara en su vuelo del 1 de diciembre de 1783 un termómetro y un barómetro, si bien más que proponerse la realización de observaciones sistemáticas y cuantitativas, se valiera de aquellos instrumentos para gobernar con seguridad la nave. Sin embargo, el alcance de su invento fue rápidamente comprendido por científicos como Priestley, quien auguró un futuro prometedor a los globos como artefactos idóneos para la investigación de las altas capas de la atmósfera; aunque algunos de los primeros viajeros en globo no se propusieran llevar a la práctica dicha idea, los aeronautas tomaron la costumbre de llevar a bordo instrumentos de medida, a los cuales pronto se encontró utilidad en labores científicas. Así, en diversos vuelos aerostáticos se pretendió medir el magnetismo terrestre, estudiar el comportamiento de los vientos, tomar datos sobre las modificaciones de la temperatura, presión y humedad de la atmósfera con la altura, etc. En algunos de ellos se llegaron a conclusiones erróneas, como ocurrió en el efectuado por Robertson y Sajarov al estudiar la supuesta pérdida de intensidad de la fuerza magnética; en otras, como las de Jeffries y Blanchard o las protagonizadas por los aerosteros de Dijon, se confirmaron algunas teorías ya existentes y se inició una práctica que pronto conduciría certeros resultados y a un perfeccionamiento de los métodos de investigación, como se demostró tras la experiencia de Biot y Gay-Lussac. Además, se extendió el ámbito de la exploración a franjas atmosféricas más extensas que las hasta entonces observadas. En gran número de ocasiones, los aeronautas portaban instrumentos que ya gozaban de suficiente aceptación en el mundo científico, llegando a hacer mediciones de un mismo parámetro con varias clases diferentes de ellos; en otras, como ocurrió en las experiencias de Dijon, fueron construidos expresamente para fines concretos. De todo ello se desprende la gran confianza que los aeronautas depositaron en un utillaje científico que habría de proporcionarles datos valiosísimos para sus indagaciones y que, con el transcurrir de los años, experimentaría mejoras o incluso ampliaría su nómina.

En España, salvo lo vuelos de Lunardi en busca de muestras de aire para su análisis químico y algunas mediciones de fenómenos atmosféricos, escasearon los vuelos de carácter científico, aunque siempre se tuvo consciencia de la importancia de llevar instrumentos a bordo y de la utilidad de los globos en la investigación científica; hubo en este sentido muchos más proyectos y sugerencias que expe- 
riencias de hecho, pero siempre estuvieron basados en razones fundadas. Por otra parte, si bien el análisis del aire tomado por el aeronauta italiano arrojó resultados decepcionantes, no se le puede restar mérito ni a él ni a su benefactor, el duque de la Roca, pues emprendió un viaje con propósitos tan firmes como loables. Tras él, la aerostación científica sufrió un fuerte retroceso, agravado por las continuas guerras y la penuria económica; sólo con la creación de la Compañía de Aerostación del Batallón de Telégrafos de Madrid por Alfonso XII en 1884, volvió aquélla a resurgir, elevando el nivel científico, técnico y militar de la aerostación espanola a una altura similar al del resto de las potencias europeas. 